\title{
EL RÉGIMEN JURÍDICO DE LAS ELECCIONES PRESIDENCIALES EN LOS ESTADOS UNIDOS
}

\author{
YOLANDA FERNÁNDEZ VIVAS \\ Profesora de Derecho Constitucional \\ Universidad de Alcalá
}

\author{
SUMARIO \\ I. Sobre el sistema electoral presidencial. \\ II. La elección de los candidatos a la presi- \\ dencia. \\ III. La elección del Presidente. \\ IV. La campaña electoral.
}

\section{SOBRE EL SISTEMA ELECTORAL PRESIDENCIAL}

El presente trabajo tiene por objeto analizar el sistema de elección del Presidente de los Estados Unidos, un sistema técnicamente complejo que presenta muchas diferencias respecto de las formas de elección que existen en las democracias occidentales de nuestro entorno. Con ello, pretendemos contribuir a suplir, de algún modo, la falta de estudios jurídicos sobre este tema, ya que, a pesar de ser dicho país un referente político indiscutible, no existen suficientes trabajos que, desde la perspectiva constitucional, estudien en profundidad el proceso para elegir a los candidatos a la presidencia norteamericana y, posteriormente, al Presidente de aquél país.

Como es sabido, los Estados Unidos son un Estado federal, integrado por los poderes centrales y cincuenta Estados que ostentan funciones legislativas y ejecutivas, y cuya forma de gobierno tiene las características propias de los sistemas presidenciales. De este modo, al existir una separación de poderes más rígida que en nuestros sistemas parlamentarios, los órganos legislativos y ejecutivos, tanto federales como estatales, son elegidos de forma independiente y mediante procesos electorales distintos, cada uno de los cuales se rige por reglas diferentes. Esto supone, en la práctica, que frecuentemente se estén convocando y celebrando diferentes procesos electorales, y que las nor- 
mas aplicables a éstos sean distintas en función del tipo de elección así como del ámbito territorial en el que se celebren los mismos ${ }^{1}$.

Así, por lo que se refiere a las elecciones presidenciales hay que comenzar indicando que tanto éstas como las elecciones al Congreso (formado por la Cámara de Representantes y Senado) son los únicos procesos electorales federales, es decir, son procesos que se celebran en todo el territorio de la Federación.

Lo que resulta más llamativo, desde nuestro punto de vista, es la inexistencia de un régimen jurídico homogéneo en todo el territorio. En el caso de las elecciones presidenciales, que son las que aquí nos interesan, la Constitución de los Estados Unidos establece las reglas básicas de elección del Presidente. Estas disposiciones mínimas, sin embargo, no han sido desarrolladas en el ámbito federal, por lo que en los Estados Unidos no existe una ley electoral federal que se aplique a todo el territorio. A dichas elecciones solamente son de aplicación ciertas normas sectoriales aprobadas por el Congreso que regulan aspectos muy concretos relacionados con el proceso electoral, y que son, únicamente, la determinación de la fecha en que ha de celebrarse la elección, la regulación de la financiación de las elecciones y el régimen de acceso de los candidatos a los medios de comunicación en periodo electoral ${ }^{2}$.

Por lo tanto, con excepción de esas reglas generales que deben cumplirse en todo el territorio, de acuerdo con la Constitución, son los propios Estados los encargados de regular el proceso electoral. Los Estados se encargan de establecer las reglas relativas a la nominación de candidatos (primarias), el acceso a las candidaturas, la distribución en distritos electorales, los requisitos que deben cumplir los electores para participar en las elecciones primarias y generales, y la estructura y tipo de las papeletas electorales, es decir, todos los elementos del proceso electoral salvo los tres anteriormente citados ${ }^{3}$. Para llevar a cabo esta función reguladora de los distintos procesos electorales, los Estados tienen total discrecionalidad, de modo que, en la práctica, esto ha llevado a la existencia de sistemas muy diversos ${ }^{4}$.

1 Hay que tener en cuenta que se celebran elecciones para elegir a los cargos representativos a nivel local, estatal y federal, además de convocar elecciones para decidir sobre otras cuestiones, como, por ejemplo, celebrar consultas populares o referenda sobre una determinada propuesta de ley, sobre la emisión de bonos del Gobierno o sobre cualquier otro asunto de política gubernamental. S. Bowler/T. Donovan/J. VAN HeERDE, "The United States of America: Perpetual Campaigning in the Absence of Competition", en M. Gallagher/ P. Mitchell, The Politics of Electoral Systems, 2008, Oxford University Press, pág. 185.

2 Las normas federales aplicables a estos procesos electorales son básicamente dos: la $\mathrm{Fe}$ deral Election Campaign Act, que regula la financiación de las elecciones, y la Communications $A c t$, que se encarga de regular el acceso de los candidatos a los medios de comunicación.

3 VVAA, "Elections", en 88 Harvard Law Review (1975), pág. 1115.

4 Aunque, por regla general no se producen problemas de aplicación de las distintas normas aplicables, en las elecciones presidenciales de 2000 se produjo una gran controversia, debido a las diferencias existentes en la normativa aplicable de los Estados, sobre todo en lo que se refería a la forma de emitir el voto así como al mecanismo de verificación de la validez de los mismos, lo que provocó que ese proceso electoral terminara en el Tribunal Supremo, que finalmente otorgó la victoria a Bush. Vid. Sentencia Bush v. Gore, 531 US 98, 104, 105 (2000). 
Centrándonos ya en las características definitorias del proceso electoral para elegir al Presidente de los Estados Unidos, hay que comenzar señalando que la Constitución sólo dispone que las elecciones presidenciales se celebran cada cuatro años y, a diferencia de lo que es comúnmente entendido, que el sistema electoral para las elecciones presidenciales es un sistema indirecto, de acuerdo con el cual los ciudadanos no eligen directamente al Presidente y Vicepresidente, sino que esta elección corresponde al denominado Colegio Electoral, formado por un número de compromisarios que representan a todos los Estados y que es el encargado de designar a las personas que ocuparán estos cargos 5 .

La idea de crear la figura del Colegio Electoral se aprobó en la Convención Constituyente, a finales del siglo XVIII, y se sigue manteniendo actualmente en la Constitución como el órgano encargado de elegir al Presidente ${ }^{6}$. La razón para ello es que se entiende que el Colegio Electoral es una manifestación del sistema federal y garantiza que el Presidente sea elegido por los Estados que integran la Federación y no por todos los ciudadanos a nivel nacional ${ }^{7}$.

El resto de elementos definitorios del sistema de elección del Presidente son obra de los legisladores de los Estados y, sobre todo, de la dinámica de los partidos políticos en aquel país. Sin extendernos demasiado, porque no es objeto de este trabajo, y desbordaría los límites del mismo, el sistema de partidos políticos en los Estados Unidos presenta diferencias notables en relación al sistema de partidos existente en Europa ${ }^{8}$. Pues bien, como luego veremos, la participación de los partidos políticos en la elección a Presidente a lo largo

5 Sobre el Colegio Electoral, vid., W. KimberLing, The Electoral College, Washington, DC: Federal Election Commission Office of Election Administration, 2003; L. Longley/N. PIERCE, The Electoral College Primer 2000, 1999, New Haven, Yale University Press.

6 En la Convención Constituyente, celebrada en Filadelfia, a pesar de las diferencias que surgieron a la hora de determinar el sistema de elección del Presidente, lo que quedó claro desde el principio era que se descartaba la posibilidad de que se celebrara una elección directa del Presidente por parte del electorado. La discusión por tanto, se centró en determinar quién se iba a encargar de la elección presidencial. Las dos opciones que se barajaron fue que el Presidente fuera elegido por el legislativo federal (como ocurre en los sistemas parlamentarios de gobierno) o bien que la elección se hiciera de forma indirecta, mediante electores o compromisarios, elegidos por los órganos legislativos de los Estados o bien por los ciudadanos. Esta última opción es la que finalmente se acordó. De este modo, el procedimiento adoptado en la Constitución estadounidense, prevé la elección del Presidente a través de compromisarios electorales, elegidos en cada uno de los Estados en una cantidad igual al número de diputados y senadores que corresponde a cada uno de los Estados en cuestión. T. H. Neale, The Electoral College: How it Works in Contemporary Presidential Elections, CRS Report for Congress, Congressional Research Service, The Library of Congress, 2003, pág. 2; W. Kimberling, The Electoral College, op. cit., págs. $2-10$.

7 S. Bowler/T. Donovan/J. VAn HeErde, "The United States of America: Perpetual Campaigning in the Absence of Competition”, op. cit., pág. 191.

8 Vid., por ejemplo, A. LijPharT, Las democracias contemporáneas, Ariel, Barcelona, 1987; M. García Pelayo, El Estado de Partidos, Alianza Editorial, Madrid, 1986; G. SARTori, Partidos y sistemas de partidos, Alianza Editorial, Madrid, 2005; L. Rebollo Delgado, Partidos politicos y democracia, Ed. Dykinson, Madrid, 2007, pág. 82. 
del tiempo ha ido definiendo un tipo de proceso electoral complejo en el que se distinguen perfectamente dos fases diferentes:

- En la primera fase se eligen los candidatos de cada partido a la presidencia de los Estados Unidos. Esta fase no se produce, como pudiera parecer, en el seno de cada partido político, sino a través de un proceso público con participación de todos los ciudadanos en el que son ellos mismos los que deciden cuál de los precandidatos que voluntariamente se presentan será el candidato del partido político correspondiente.

- En la segunda fase, una vez elegidos los candidatos de cada partido político, tiene lugar la contienda electoral entre ellos, que finaliza con la jornada electoral y la posterior designación del Presidente a través del Colegio Electoral'.

\section{LA ELECCIÓN DE LOS CANDIDATOS A LA PRESIDENCIA}

\section{INTRODUCCIÓN}

Uno de los rasgos que caracterizan el sistema electoral norteamericano es la amplia participación de los ciudadanos, que no sólo se manifiesta en la jornada electoral ejerciendo el derecho de sufragio, sino que resulta decisiva en la fase previa de elección del candidato a la presidencia por parte de cada uno de los partidos políticos. Aquí observamos una de las grandes diferencias con los sistemas políticos europeos, en los que la elección de los candidatos a la presidencia del gobierno se realiza mediante procedimientos internos en el seno de los partidos políticos en los que únicamente participan los afiliados de ese partido o los órganos de dirección del mismo ${ }^{10}$.

La elección de los candidatos de cada uno de los partidos políticos a la presidencia de los Estados Unidos se rige por las normas de los distintos Estados así como por las disposiciones de los propios partidos. En este sentido, y como ya hemos señalado, no existe un sistema homogéneo, y en cada uno de los Estados se establecen los requisitos para poder presentarse como precandidato, el tipo de sistema que se utiliza para elegir a los precandidatos (elecciones primarias o caucus), la fecha de celebración de las elecciones primarias, el tipo de papeleta electoral, si el sistema es mayoritario o proporcional, etc.

9 J. C. Plano/M. Greenberg, The American Political Dictionary, Holt, Rinerhat and Winston Eds., 1978, pág. 140.

10 R. Blanco Valdés, Los partidos políticos, Ed. Tecnos, Madrid, 1990, pág. 82; E. Espín TemPLADO, «Una reflexión sobre la representación política y los sistemas electorales en las democracias constitucionales", en G. RuIz Rico / S. Gambino (Coords.), Formas de gobierno y sistemas electorales, Ed. Tirant Lo Blanch, Valencia, 1997, pág. 36; C. Rossano, Problemi di struttura dello Stato sociale contemporaneo. Lezioni di dottrina dello Stato, Eugenio Jovene Editore, Nápoles, 1978. 
No obstante, y a pesar de que existen diferencias entre unos y otros Estados a la hora de regular aspectos concretos sobre esta fase previa de elección de los candidatos de los partidos, en todos los casos el proceso por el que se elige a los candidatos de los partidos políticos a la presidencia de los Estados Unidos se desarrolla de la siguiente manera:

1. En primer lugar, se produce la fase de prenominación, en la que cualquier persona con aspiraciones políticas, y en muchos casos, sin necesidad de estar afiliado al partido político, puede presentarse voluntariamente como precandidato.

Esta fase de prenominación se desarrolla a través de dos sistemas distintos, las elecciones primarias y los caucuses. En las elecciones primarias, los ciudadanos eligen de entre los precandidatos y votan por uno de ellos. Por su parte, en el caucus, o asamblea electoral, se reúnen los afiliados o simpatizantes del partido político y muestran su apoyo a un determinado precandidato. Cada Estado decide qué sistema utiliza para llevar a cabo la prenominación, el sistema de primarias o los caucuses. Lo habitual es que se opte por el sistema que tradicionalmente se haya utilizado para elegir a los candidatos en ese Estado, aunque algunos Estados exigen por ley que la prenominación se realice mediante uno de estos sistemas, generalmente mediante primarias.

En todo caso, y con independencia de que la elección se haga mediante elecciones primarias o caucuses, en esta fase los precandidatos compiten entre sí para lograr obtener delegados que les representen en la convención nacional del partido. Es decir, en ambos casos, el apoyo popular que obtiene cada uno de los precandidatos se traduce en delegados. A cada uno de los Estados les corresponde un número determinado de delegados. Pues bien, al precandidato que haya obtenido más votos (en el caso de las elecciones primarias), o más apoyo en el caucus, se le atribuyen los delegados de ese Estado, que le representarán y votarán por él en la convención nacional del partido.

2. En segundo lugar, y una vez concluida la celebración de primarias y caucuses en todos los Estados, cada uno de los partidos políticos celebra su propia convención nacional, en la que se elige a los candidatos a la Presidencia y Vicepresidencia. Estas convenciones nacionales están formadas por los delegados (que se han elegido, como hemos visto, a través de primarias y caucuses) y por otros miembros de dirección del partido, conocidos como superdelegados. Todos ellos participan en la convención y cada uno de ellos vota por el precandidato al que representa. Finalmente, el precandidato que obtenga la mayoría de votos en la convención es el elegido como candidato a la presidencia por ese partido y competirá en las elecciones presidenciales.

Para comprender mejor las características de este complejo sistema de elección de los candidatos de cada partido político a la presidencia, es preciso analizar cuál ha sido la evolución histórica seguida para este tipo de elecciones hasta llegar al diseño actual de las mismas. 


\section{ORIGEN Y EVOLUCiÓN HistÓRICA DEL SISTEMA DE ELECCIÓN DE LOS CANDIDATOS A LA PRESIDENCIA}

El procedimiento a través del cual se elige a los candidatos electorales de cada uno de los partidos ha ido evolucionando y se ha ido perfeccionando a lo largo del tiempo, en base a la experiencia acumulada y teniendo en cuenta, sobre todo, la idea de fomentar una mayor participación directa de los ciudadanos.

\subsection{La elección de los precandidatos a través de los caucus}

El origen de los sistemas de elección a cargos públicos representativos en los Estados Unidos se sitúa en el periodo colonial, antes incluso de la declaración de independencia. Durante este periodo, la elección de los cargos públicos se desarrollaba en el denominado "caucus club", formado por la élite del partido patriótico, el único que funcionaba como tal en aquellos días, y que celebraba distintas asambleas o reuniones en las que se discutían y se acordaban los nombres de los candidatos a los cargos públicos cuyo nombramiento le correspondía efectuar a las colonias. Una vez acordados los nombres de los candidatos, los miembros del "caucus club" fijaban en las listas los nombres acordados y posteriormente los distribuían en el día de la elección. De este modo, salían elegidos los candidatos propuestos por el cau$\mathrm{cus}^{11}$.

Tras la declaración de independencia y la aprobación de la Constitución, se mantuvo el sistema de caucus para elegir a los cargos públicos representativos. En este sentido, para elegir a las personas que ocuparían esos cargos, se celebraban distintas asambleas públicas, en las que participaban todos los ciudadanos. Sin embargo, en la práctica, el poder de estas asambleas vecinales era muy limitado, ya que pronto se descubrió que los líderes políticos de los partidos, o, en algunos casos, los caciques locales, se reunían previamente y decidían los nombres de los candidatos, con lo que el poder real de decisión de estas asambleas vecinales resultó prácticamente nulo.

Debido a los múltiples casos de corrupción en los cargos públicos que se fueron conociendo, se optó por modificar el sistema. Así, a finales del siglo xviII la elección de los candidatos para los cargos públicos representativos se encomendó a los denominados "caucuses congresionales", también llamados "caucuses legislativos". Estos caucuses estaban formados por los miembros del Congreso (Cámara de Representantes y Senado) de cada uno de los partidos. Los diputados y senadores del partido se reunían en cada uno de los Estados y decidían los nombres de los candidatos de su partido a ocupar los cargos públicos representativos.

11 A. M. Schlesinger JR., History of American Presidential Elections, Vol. I, New York, McGraw-Hill, 1971, págs. 249 y ss. 
Este sistema de nominación mediante caucus empezó a decaer a principios del siglo XIX, especialmente cuando desapareció el Partido Federalista, quedando solamente un único partido con posibilidades de ganar las elecciones, la coalición demócrata-republicana. Se daba entonces la circunstancia de que el candidato elegido por el caucus de ese partido tenía garantizada la presidencia. Así ocurrió en dos procesos electorales, en 1816 y 1820, con las dos victorias de James Monroe. Ante esta situación se multiplicaron las protestas por parte de los ciudadanos estadounidenses, que solicitaban participar en la elección del Presidente y no dejar la nominación en manos de los políticos, y, más concretamente, de un partido político ${ }^{12}$.

\subsection{La elección en las convenciones nacionales}

En la década de 1830, se produjo una reforma en las costumbres y procedimientos de elección de los candidatos de los partidos a la presidencia, que consistió básicamente en sustituir el sistema de caucus por las convenciones nacionales de los partidos ${ }^{13}$. Este procedimiento de reforma fue impulsado por el presidente Andrew Jackson ${ }^{14}$, y consistía en que la selección de los candidatos de cada partido se realizaba mediante las convenciones nacionales de los mismos ${ }^{15}$.

Este sistema de elección consistía en la celebración por parte de los partidos políticos de distintas convenciones, primero a nivel local, después a nivel estatal y, finalmente, a nivel nacional, para elegir al candidato del partido.

Así, en primer lugar se celebraban distintas reuniones y asambleas de los partidos en el ámbito local, en las que se reunían los responsables de los partidos a nivel local, los afiliados, así como los representantes elegidos en localidades más pequeñas. En ellas se elegía a los delegados que iban a representarles en la convención estatal. En segundo lugar, una vez celebradas todas las convenciones o asambleas locales, los partidos políticos iban celebrando convenciones en cada uno de los Estados. Estas convenciones estaban compuestas por delegados elegidos en cada una de las convenciones locales, y, a su vez, elegían a los delegados que iban a representarles en la Conven-

12 N. Polsby, Consequences of Party Reform, New York, Oxford University Press, 1983.

13 Llama la atención que el primer partido político que celebró una convención para elegir a su candidato a la presidencia fue el Partido Antimasónico, en 1831.

14 El Presidente Jackson, que obtuvo la victoria en las elecciones presidenciales de 1828 , modificó el sistema de elección de los candidatos a la presidencia, debido a que su candidatura fue rechazada en el caucus congresional demócrata para las elecciones presidenciales de 1824. Vid., en este sentido, J. C. Plano/M. Greenberg, The American Political Dictionary, op. cit., pág. 117.

15 Las primeras convenciones para elegir al candidato a la presidencia por parte de uno de los partidos mayoritarios, el partido demócrata, se celebró en 1832 en Baltimore, Maryland. Sobre las convenciones nacionales, vid., J. W. DAVIS, National Conventions in an Age of Party Reform, Westport, Greenwood Press, 1983. 
ción nacional del partido. Finalmente, se celebraba la Convención nacional del partido, compuesta por los delegados elegidos en las convenciones estatales, y que es a la que correspondía la nominación del candidato del partido a la presidencia.

El sistema de elección mediante las convenciones se mantuvo durante todo el siglo XIX, hasta principios del siglo $\mathrm{xx}^{16}$.

\subsection{La elección mediante elecciones primarias}

Hasta comienzos del siglo xx, los partidos políticos controlaban la selección y la nominación de sus candidatos, ya fuera mediante el sistema de caucus o a través de las convenciones. Sin embargo, estos sistemas de elección causaban gran insatisfacción entre los ciudadanos, que consideraban que los aparatos de los partidos elegían a los candidatos no por su valía, sino porque en un momento dado pudieran ser más fácilmente manipulables, en especial en el caso de los cargos públicos representativos a nivel local o comarcal, en los que la corrupción y el caciquismo eran algo habitual. Algo similar ocurría con la selección de delegados en las convenciones, que estaban sometidos a una compleja red de presiones y negociaciones, y que respondían a las exigencias de los líderes del partido estatal. Por ello, para acabar con lo que se denominaban los "mercados políticos", y viendo la necesidad de luchar contra la corrupción municipal y estatal, se puso en marcha la celebración de elecciones primarias para elegir a los precandidatos de los partidos $^{17}$.

La reforma del sistema de elección de los candidatos tenía como objetivo arrebatar a los partidos el control de las nominaciones de los candidatos a la presidencia y dejar esta función en manos de los votantes ${ }^{18}$. En este sentido, las elecciones primarias simbolizaban una verdadera participación popular en el proceso previo de elección entre los precandidatos y sirvieron para restaurar la competitividad política en el proceso electivo, ya que eran los ciudadanos los encargados de elegir directamente, mediante una votación, al candidato de cada uno de los partidos de entre todos los que se hubieran presentado. De este modo, la intervención de los partidos quedaba mucho más limitada, pues se reducía a la celebración de la convención nacional para designar al candidato.

16 Las mayores críticas sobre este sistema de elección de los candidatos a la presidencia mediante las convenciones se basaban en que los candidatos eran elegidos por la organización del partido, a nivel estatal o nacional y, por tanto, no reflejaban realmente el voto popular. K. J. Coleman/J. E. Cantor/T. H. Neale, Presidential Elections in the United States: A Primer, CRS Report for Congress, Congressional Research Service, The Library of the Congress, 2000, pág. 17.

17 R. Hofstadter, The Age of Reform, 1956, New York, Vintage; S. Bowler/ T. Donovan/J. VAN HEerde, "The United States of America: Perpetual Campaigning in the Absence of Competition", op. cit., pág. 189.

18 W. D. BuRnham, Critical Elections and the Mainsprings of American Politics, 1970, New York, W. W. Norton. 
El sistema de primarias consistía en lo siguiente: en primer lugar, se convocaban elecciones primarias en cada uno de los Estados, a las que se presentaban varios precandidatos. Los ciudadanos votaban en su localidad al precandidato elegido. Finalizada la jornada electoral, el precandidato que hubiera obtenido más votos en el Estado era quien obtenía los delegados correspondientes a ese Estado, y estos delegados, posteriormente, le representarían y apoyarían en la convención nacional del partido. En segundo lugar, una vez efectuadas todas las votaciones primarias, se celebraba la convención nacional del partido, en la que participaban los delegados en representación de cada uno de los Estados. Era en ese momento cuando formalmente el partido político elegía a su candidato a la presidencia.

En 1904 el Estado de Florida se convirtió en el primer Estado que exigió a los partidos políticos que designaran a sus delegados mediante una elección estatal primaria, financiada con fondos públicos ${ }^{19}$. Este sistema de las primarias se extendió rápidamente y en 1916 ya había sido adoptado por 24 Estados. Sin embargo, en las décadas de los 40 y 50 decayó notablemente, principalmente porque a pesar de que existían procesos de primarias en buena parte de los Estados (aproximadamente la mitad de los Estados habían incorporado esta exigencia en sus normas electorales), los partidos políticos seguían controlando, de facto, la nominación de los candidatos en las convenciones nacionales, ya que los delegados que integraban esas convenciones seguían fuertemente vinculados al partido político ${ }^{20}$.

Esta situación cambió a finales de los años 60 , cuando tras comprobarse que en las convenciones existía una presencia importante, y a veces decisiva, de delegados designados directamente por los caciques políticos estatales, los dos partidos mayoritarios decidieron reformar el sistema de selección de delegados, generalizando el sistema de primarias para la elección de los delegados y limitando el número de los que elegía el partido político. Así, en las elecciones de 1988 cerca del 80\% de los delegados de cada uno de los partidos en las convenciones nacionales fueron elegidos mediante primarias ${ }^{21}$.

Así pues, como resultado de esta evolución histórica, el sistema de elección de los candidatos a la presidencia de los Estados Unidos sigue manteniendo, como ya hemos dicho, dos fases claramente diferenciadas. La primera fase, la "fase de prenominación", en la que los precandidatos compiten para lograr delegados que les representen en la convención nacional del partido; y la segunda fase, la celebración de la convención nacional de los partidos políticos, en la que formalmente se elige al candidato a la presidencia de cada uno de los partidos y se ratifica el programa electoral del mismo. Por lo que respecta a la fase de prenominación, se mantienen los dos sistemas de elec-

19 K. J. Coleman/J. E. Cantor/T. H. Neale, Presidential Elections in the United States: A Primer, op. cit., pág. 11.

20 J. C. Plano/M. Greenberg, The American Political Dictionary, op. cit., págs. 120 y 141.

21 L. S. Rothenberg/R. A. Brody, "Participation in Presidential Primaries", en Western Political Quarterly, 41:2 (1988: June), pág. 253; J. Bello/R. Y. SHAPIRO, "On To the Convention", en Political Science Quarterly, Volume 123, Number 1, 2008, pág. 1 y ss. 
ción, los caucuses y las elecciones primarias, aunque estas últimas están más extendidas ${ }^{22}$.

\section{REQUisitos PARA SER CANDIDATO A LA PRESIDENCIA}

Una vez expuestas las fases del sistema de elección de los candidatos a la presidencia, corresponde analizar quién puede presentarse como candidato, qué requisitos tiene que cumplir y cómo es el procedimiento para presentar la candidatura.

\subsection{El derecho a ser candidato electoral}

La Constitución estadounidense no reconoce de manera expresa el derecho de sufragio pasivo, o, lo que es lo mismo, el derecho a ser candidato electoral, aunque nadie duda de su reconocimiento constitucional. En este sentido, el Tribunal Supremo ha afirmado que el derecho de sufragio pasivo deriva del derecho de asociación política consagrado en la Primera Enmienda de la Constitución ${ }^{23}$.

Los requisitos para ser candidato a la Presidencia se establecen, en primer lugar, en la propia Constitución. Así, el artículo II sección 1 de la Constitución norteamericana dispone que todo candidato a Presidente de los Estados Unidos debe ser un ciudadano natural de los Estados Unidos ${ }^{24}$, tener al menos 35 años de edad y haber sido residente en los Estados Unidos, al menos, durante 14 años. Por su parte, los candidatos a Vicepresidente han de cumplir con los mismos requisitos exigidos al candidato a Presidente. Además, la Constitución exige que el Vicepresidente no sea del mismo Estado que el Presidente ${ }^{25}$.

En segundo, lugar, los Estados son libres para establecer requisitos o condiciones adicionales que tienen que cumplir quienes quieran presentarse como candidatos electorales en dichos Estados, aunque, eso sí, respetando lo

22 En la actualidad, más del 90\% de los candidatos y delegados son elegidos mediante elecciones primarias, tanto por parte del partido republicano como del demócrata K. J. Coleman/J. E. Cantor/T. H. Neale, Presidential Elections in the United States: A Primer, op. cit., pág. 12.

23 Sentencia Williams v. Rhodes, 393 US 23, 30 (1968); Sentencia Lubin v. Panish, 415 US 709 (1974). En la doctrina, L.H. Tribe, American Constitutional Law, Foundation Press, 1988, pág. 1111; J.H. WILKINSON, "The Supreme Court, the Equal Protection Clause, and the Three Faces of Constitutional Equality", en 61 Virginia Law Review (1975), págs. 945-1018, pág. 957; R. BRIFFAULT, "Bush v. Gore as an equal protection case", en 29 Florida State University Law Review (2001), pág. 347; VVAA, "Elections”, op. cit., pág. 1218.

24 La doctrina mayoritaria ha interpretado que se cumple con este requisito también siempre que los padres sean ciudadanos de los Estados Unidos, aunque el candidato no haya nacido en territorio estadounidense. Por otro lado, se considera que los ciudadanos nacidos en Guam, Puerto Rico y las Islas Vírgenes también tienen la consideración de naturales de los Estados Unidos. Vid., en este sentido, K. J. Coleman/J. E. Cantor/T. H. Neale, Presidential Elections in the United States: A Primer, 2000, op. cit., pág. 2.

25 XII Enmienda a la Constitución norteamericana. 
establecido en la Constitución. Así se ha pronunciado el Tribunal Supremo al reconocer que los Estados están legitimados para establecer ciertas condiciones en aras a tener un mejor control del proceso electoral, siempre que esas condiciones o medidas no limiten de manera desproporcionada la igualdad de los partidos minoritarios o de los candidatos electorales en la competición política ${ }^{26}$. Por otro lado, el Tribunal ha afirmado que, en caso de conflicto, los derechos individuales que protege la Constitución —entre ellos el derecho de sufragio y el derecho de asociación política - prevalecen sobre los intereses legítimos de los Estados de regular el derecho de sufragio pasivo ${ }^{27}$.

Las Leyes electorales de los Estados prevén una serie de requisitos que han de cumplir los ciudadanos que quieren presentar su candidatura electoral, requisitos que podemos agrupar en las siguientes categorías: en primer lugar, determinadas condiciones económicas ${ }^{28}$, en segundo lugar, condiciones de residencia $^{29}$; en tercer lugar, poseer determinadas propiedades ${ }^{30} ; \mathrm{y}$, por último, estar afiliado a un partido político ${ }^{31} \mathrm{o}$ demostrar un determinado apoyo de los ciudadanos $^{32}$. Resulta cuanto menos llamativo, desde la perspectiva europea, con partidos políticos mucho más organizados, que la afiliación al partido político no sea una exigencia para presentarse como candidato, de modo que una persona puede presentar su candidatura por un determinado partido político sin estar afiliado al mismo.

Los motivos que justifican la exigencia de estos requisitos por parte de los Estados han sido muy dispares, aunque podemos resaltar los siguientes: en primer lugar, estos requisitos hacen que disminuya el número de candidaturas electorales que se presentan, lo que reduce potencialmente la confusión del

26 Sentencia Lubin v. Parnish, 415 US 709, 716 (1974); Sentencia Lassiter v. Northampton County Board of Elections, 360 US 45 (1959). En la doctrina, R. BRIFFAULT, "Bush v. Gore as an equal protection case", op. cit., pág. 346; J. E. NowAK/R. D. Rotunda, Constitutional Law, West Editors, 1995 , pág. 881 y 885 .

27 Sentencia Williams v. Rhodes, 393 US 23, 30 (1968); Sentencia Bush v. Gore, 531 US 98, 104, 105 (2000); en la doctrina, vid. R. BRIFFAult, "Bush v. Gore as an equal protection case", op. cit., pág. 356; R.L. HASEN, "Bush v. Gore and the future of equal protection law in elections", en 29 Florida State University Law Review (2001), págs. 388-389.

28 Por ejemplo, algunos Estados exigen a los potenciales candidatos que abonen una tasa, una cantidad económica con carácter previo a la proclamación de su candidatura. Vid. Sentencia Harper v. Virginia Bd. of Elections, 383 US 663 (1966).

29 Por ejemplo, se establece que los candidatos tengan su residencia en el Estado al que se presenten a las elecciones durante un determinado periodo de tiempo. Vid. Sentencia Dunn $v$. Blumstein, 405 US 330 (1972).

30 Esta exigencia fue considerada inconstitucional por el Tribunal Supremo, al estimar que iba en contra de la equal protection clause. Vid. Sentencia Hill v. Stone, 421 US 289 (1975); City of Phoenix v. Kolodziejski, 399 US 204 (1970).

31 Esta condición o exigencia requiere que las personas que quieran concurrir a las elecciones deben ser miembros de un partido político. Este requisito, para un sector de la doctrina supone una discriminación de los partidos mayoritarios respecto de los candidatos independientes. Vid., en este sentido, VVAA, "Elections", op. cit., págs. 1124-1125.

32 Esta condición se exige especialmente para los candidatos independientes y para los partidos políticos minoritarios y consiste en la presentación de un número de firmas que acrediten que dicho candidato o partido tiene respaldo popular. 
votante; en segundo lugar, al limitar el número de posibles candidatos se asegura que el vencedor recibirá la mayoría del voto popular, obteniendo así el Gobierno mayor apoyo y confianza; en tercer lugar, se afirma que los Estados no tienen un interés especial en reducir o minimizar el número de candidatos que concurren en el proceso electoral, pero sí que tienen un especial interés en lograr la estabilidad política; y, por último, se considera que la restricción del derecho de sufragio pasivo evita que aparezcan candidatos "frívolos" y preserva, de esa manera, la integridad del proceso electoral ${ }^{33}$. Todos estos argumentos han sido admitidos por el Tribunal Supremo, que ha interpretado que los Estados tienen intereses legítimos suficientes como para imponer restricciones en el derecho de sufragio pasivo, siempre que esas restricciones estén justificadas y no sean contrarias a la "equal protection clause, ${ }^{34}$.

No existen más requisitos legales que los ya citados, pero la práctica ha demostrado que para presentarse como candidato a la presidencia es necesario haber ocupado previamente otros cargos políticos, en el gobierno o en el partido, ya sea a nivel estatal o federal. Así, todos los Presidentes electos de los Estados Unidos (incluido el recientemente elegido Obama) han desempeñado otros cargos públicos representativos antes de iniciar su carrera a la Casa Blanca ${ }^{35}$.

\section{Presentación de Candidaturas}

Con carácter previo a que se inicie el proceso para elegir a los candidatos de cada uno de los partidos a la presidencia, todos aquellos con aspiraciones políticas a ocupar ese puesto comienzan a movilizarse.

La primera nota que resulta llamativa es que la elección de los candidatos, como ya hemos indicado, no recae en los partidos políticos, sino en los ciudadanos. Los dos principales partidos políticos han rechazado elegir directamente desde el partido a los candidatos, dejando esa tarea de nominación a los electores. De este modo, cualquier persona que, en principio, cumpla con los requisitos previstos en la Constitución y en las leyes electorales de los Estados puede "autoproclamarse" precandidato para intentar lograr en la fase previa de primarias y caucuses suficientes delegados para ser nominado, es decir, elegido como candidato del partido ${ }^{36}$. Por eso, y aunque

33 Sentencia Storer v. Brown, 415 US 724, 732 (1974); Sentencia Anderson v. Celebreeze, 460 US 780 (1983); J. E. NowaK/R. D. Rotunda, Constitutional Law, op. cit., pág. 881; L. H. TRIBE, American Constitutional Law, op. cit., pág. 1643.

34 Sentencia Illinois State Board of Elections v. Socialist Workers Party, 440 US 173 (1979). L.H. TRIBE, American Constitutional Law, op. cit., pág. 1101; J. H. Wilkinson, "The Supreme Court, the Equal Protection Clause, and the Three Faces of Constitutional Equality", op. cit., pág. 958.

35 Entre los cargos que habían ocupado previamente nos encontramos con Vicepresidentes (Roosevelt, Coolidge, Truman, Johnson o Ford); Gobernadores (Wilson, Roosevelt, Carter, Reagan, Clinton), Senadores (Harding, Kennedy, Obama).

36 K. J. Coleman/J. E. Cantor/T. H. Neale, Presidential Elections in the United States: A Primer, op. cit., págs. 2 y 3. 
sean datos poco conocidos, lo cierto es que normalmente son muchos los precandidatos que se presentan, comienzan a recaudar fondos para financiar su campaña y organizan todo lo necesario para presentarse a las primarias y caucuses $^{37}$.

El anuncio oficial de presentación de la precandidatura generalmente viene precedido de un periodo previo en el que los precandidatos sondean sus posibilidades. Para ello, crean distintos comités preparatorios para calibrar el apoyo popular hacia su candidatura.

Llama la atención que no existe un plazo predeterminado para presentar precandidaturas, pues esto depende mucho de la estrategia política del precandidato y también de la decisión de los partidos acerca de las fechas para convocar las elecciones primarias ${ }^{38}$. Por ello, los precandidatos analizan el momento en el que deben anunciar su candidatura, sobre todo teniendo en cuenta el impacto político que ésta puede causar.

Ahora bien, una vez que los precandidatos anuncian formalmente su precandidatura, quedan sometidos al control de las normas federales en materia de financiación y de acceso a los medios de comunicación ${ }^{39}$. Así, todos los precandidatos han de registrarse en la Federal Election Commission (FEC), que es el organismo encargado de fiscalizar la financiación de los candidatos $^{40}$.

Los requisitos formales que han de cumplir los precandidatos para presentar sus candidaturas y ser calificados como tales son diferentes en cada uno de los Estados, y varían en función de si el Estado elige a los candidatos mediante elecciones primarias o mediante el sistema de caucus. Por regla general, los precandidatos presentan una declaración de candidatura ante el Secretario de Estado o ante el presidente del partido a nivel estatal. En los Estados en los que se celebran elecciones primarias, el Secretario de Estado (o, en su caso, el responsable de la oficina electoral) es quien se encarga de comprobar si el precandidato cumple con los requisitos para ser calificado como tal y, en ese caso, incluye su nombre en la papeleta electoral para que pueda participar en las primarias de uno de los partidos ${ }^{41}$. Por su parte, en los Estados que celebran

37 De acuerdo con los datos de la Federal Election Commission, 147 personas presentaron su candidatura en las últimas elecciones presidenciales de 2008.

38 En la actualidad es común que la elección del candidato a la presidencia esté claro antes de que se celebre la convención nacional del partido, es decir, durante el periodo de primarias, de modo que las elecciones primarias cada vez se van programando con más antelación, lo que hace que los candidatos tengan que presentar su candidatura también mucho antes.

3947 U.S.C. 315 (a).

40 Cualquier persona puede registrarse en la FEC en el plazo de 15 días desde el momento en el que haya alcanzado el umbral de ingresos (5.000\$) y debe nombrar un comité de campaña, que, a partir de ese momento, será el encargado de recibir las donaciones y aportaciones financieras a su campaña así como de efectuar los gastos de la misma. 5 U.S.C. $\ 431$ (2).

41 En las papeletas electorales durante el proceso de primarias figuran los nombres de los candidatos de los partidos mayoritarios, de los candidatos que han sido calificados como tales en otros Estados, así como de los candidatos independientes que se han registrado en la FEC o que sean susceptibles de recibir matching funds. K. J. Coleman/J. E. Cantor/T. H. Neale, Presidential Elections in the United States: A Primer, op. cit., pág. 4. 
caucus, los partidos políticos son los que se encargan de organizar los procedimientos para que los precandidatos puedan presentar su candidatura.

\section{El proceso de elección de los Candidatos a la Presidencia}

Como ya hemos visto, las elecciones primarias y los caucuses constituyen la primera fase del proceso electoral. A lo largo de esta fase previa de prenominación, los precandidatos de cada uno de los partidos compiten entre sí para obtener el mayor número de delegados posibles en la Convención nacional, que es la que finalmente debe elegir al candidato del partido a la presidencia. Dependiendo de las normas electorales de cada Estado, este proceso se realiza mediante elecciones primarias o caucuses.

Esta primera fase juega un papel esencial en el proceso electoral por dos motivos. El primero, porque durante el transcurso de la misma se va reduciendo el número de precandidatos por cada uno de los partidos. El segundo, porque, a pesar de que, formalmente, la elección del candidato del partido a la presidencia se realiza en la convención nacional, en la práctica, es habitual que un candidato obtenga la mayoría suficiente de delegados antes de que finalice esta primera fase, es decir, antes de que finalicen las primarias o los caucuses, o, en todo caso, antes de que se celebre la convención. Por lo tanto, es esta primera fase la que tiene una mayor trascendencia política.

\subsection{Elecciones primarias}

\subsubsection{Concepto y regulación}

Las elecciones primarias consisten en la convocatoria por parte de cada uno de los partidos políticos de elecciones en todos los Estados, en las que los ciudadanos, ya sean afiliados o no a ese partido, emiten su voto y otorgan su apoyo a un determinado precandidato de entre todos los que se hayan presentado. Con este sistema, los partidos políticos comprueban el apoyo popular que tiene cada uno de los precandidatos; además, ese apoyo popular se traduce posteriormente en la adjudicación de delegados, que representarán al candidato en la convención nacional del partido.

Las elecciones primarias presentan en los Estados Unidos muy diversas modalidades, conforme a las respectivas regulaciones estatales y las prácticas de los partidos políticos ${ }^{42}$.

42 B. Cain/M. Muluin, "Strategies and Rules: Lessons from the 2000 Presidential Primaries", en B. CAIN/ E. GERBER (Eds.), Voting at the Political Fault Line: California's Experiment with the Blanket Primary, Berkeley, University of California Press, 2002. S. Bowler/T. Donovan/J. VAn HeErde, "The United States of America: Perpetual Campaigning in the Absence of Competition", op. cit., pág. 189. 


\subsubsection{Tipos de primarias}

Existen diferentes tipos de elecciones primarias, de acuerdo con la regulación establecida en cada uno de los Estados. Con carácter general, podemos distinguir entre elecciones primarias cerradas o abiertas en función de quiénes pueden participar en este tipo de elecciones.

Las elecciones primarias cerradas son aquellas en las que sólo pueden participar los afiliados del partido político ${ }^{43}$, o en las que participan los afiliados del partido así como aquellos electores que no están afiliados al mismo, pero que han declarado su apoyo a éste ${ }^{44}$. Este tipo de elecciones cerradas se caracteriza porque el elector ha de estar registrado como miembro del partido, $\mathrm{O}$, al menos, declarar su filiación partidista ${ }^{45}$, por lo que a la hora de votar en las primarias recibirá únicamente la papeleta de su partido ${ }^{46}$. Las elecciones primarias cerradas son las más extendidas.

Las elecciones primarias abiertas, son aquellas en las que pueden participar todos los ciudadanos ${ }^{47}$. En algunos casos se exige a los electores que hagan una declaración pública de que van a votar por ese partido ${ }^{48}$, pero en otros casos ni siquiera se exige esa declaración previa, abriéndose, por tanto, la posibilidad de que cualquier persona que quiera pueda participar en el proceso de primarias de cualquier partido. En el caso de las elecciones primarias abiertas, a los electores se les entregan las papeletas de los dos partidos, aunque sólo podrán participar en la nominación de uno de ellos ${ }^{49}$.

Junto con estos dos tipos de elecciones primarias, existe un tercer tipo denominado "blanket primary", en el que los votantes pueden participar en el proceso de elección de los precandidatos de los dos partidos políticos, sin necesidad de estar afiliado ni mostrar públicamente su adhesión a ninguno de ellos $^{50}$. Este tipo de elección primaria fue utilizado por los Estados de Alaska, California y Washington hasta finales del siglo xx, pero cambiaron de sistema

43 Quince Estados celebran este tipo de elecciones: Alaska, California, Conneticut, Dakota del Sur, Delaware, Kentucky, Maine, Nebraska, Nevada, New Jersey, Nuevo México, Nueva York, Oklahoma, Pennsylvania, y Wyoming.

44 Trece Estados utilizan este sistema de primarias: Arizona, Carolina del Norte, Colorado, Florida, Iowa, Kansas, Maryland, Massachussets, New Hampshire, Oregón, Rhode Island, Utah y West Virginia.

45 Hay que indicar que la identificación partidista que se solicita de los electores es, de hecho, una mera formalidad no controlable.

46 J. C. Plano/M. Greenberg, The American Political Dictionary, op. cit., pág. 118.

47 R. HARO, "Elecciones primarias abiertas. Apuntes para una mayor democratización del sistema político", en Revista de Estudios Políticos, núm. 78, Octubre-Diciembre, 1992, pág. 273.

48 Utilizadas en once Estados: Alabama, Arkansas, Carolina del Sur, Georgia, Illinois, Indiana, Mississippi, Ohio, Tennessee, Texas y Virginia.

49 S. Bowler/T. Donovan/J. VAn HeErde, "The United States of America: Perpetual Campaigning in the Absence of Competition", op. cit., pág. 190; J. C. Plano/ M. GreEnberg, The American Political Dictionary, op. cit., pág. 135.

50 J. C. Plano/M. Greenberg, The American Political Dictionary, op. cit., pág. 123. 
tras la Sentencia del TS que declaró que este sistema de elección era inconstitucional ${ }^{51}$.

\subsubsection{Procedimiento de celebración de las elecciones primarias}

Por lo que se refiere al procedimiento de celebración de las primarias, los partidos políticos se encargan de presentar un calendario con diversas posibles fechas de celebración de las elecciones, aunque la decisión final les corresponde a los Estados, ya que son éstos los que se encargan de financiar con fondos públicos las mismas ${ }^{52}$. En este sentido, llama la atención que en el último proceso electoral de 2008, 24 Estados decidieron fijar la fecha de las primarias en la primera jornada propuesta por los partidos ${ }^{53}$.

El primer Estado que celebra elecciones primarias es el Estado de New Hampshire, que, junto con el Estado de Iowa, que utiliza el sistema de caucus, son los dos Estados que históricamente han iniciado las votaciones. Esta tradición es respetada por todos los Estados y a la hora de planificar la celebración de las elecciones primarias en todo el país se tiene en cuenta esa circunstancia $^{54}$. No hay que olvidar que cada vez es más relevante, desde el punto de vista político, el momento en el que se celebran las elecciones primarias, ya que los resultados que se obtienen en las primeras que se van convocando suelen influir en las votaciones posteriores. Por eso, la mayoría de los Estados van adelantando cada vez más la convocatoria de las elecciones primarias en su territorio para conseguir una mayor influencia ${ }^{55}$. Además, en las últimas convocatorias electorales se ha comprobado que las últimas primarias eran irrelevantes a la hora de elegir al precandidato, pues se daba la circunstancia de que un precandidato había logrado ya los delegados necesarios para lograr su nominación en la convención nacional del partido.

\subsubsection{La atribución de delegados}

El objetivo de las elecciones primarias es contribuir a la elección del candidato de un determinado partido político a la presidencia, mediante la com-

51 Este sistema se consideró contrario a la Constitución al entender que con este sistema se corre el riesgo de que votantes de uno de los partidos votasen al candidato más débil del partido contrario como estrategia política en beneficio de su propio partido. Sentencia California Democratic Party v. Jones, 530 U.S. 567 (2000). En la doctrina, sobre las "blanket primaries", vid. B. CAIn/E. GERBER (Eds.), Voting at the Political Fault Line: California's Experiment with the Blanket Primary, op. cit..

52 Así, por ejemplo, en las últimas elecciones presidenciales de 2008, el Estado de Kansas decidió no celebrar elecciones primarias, con el fin de ahorrar dos millones de dólares. En respuesta a esta decisión, los partidos demócrata y republicano se encargaron de organizar y celebrar sus propios caucuses en ese territorio.

53 Ese día fue el martes 5 de febrero, denominado "Súper Martes".

54 C. BRERETON, First in the Nation: New Hampshire and the Premier Presidential Primary, Porstmouth, N. H., Peter Randall Publishers, 1987. 
petición electoral entre los distintos precandidatos. Ahora bien, el precandidato que obtiene más votos en las primarias no es automáticamente elegido candidato por el partido a la presidencia, sino que, para que se produzca la nominación del candidato, éste debe conseguir delegados que le representen y voten por él en la convención nacional del partido político.

Los delegados son, generalmente, personas relacionadas con el partido a nivel estatal o responsables de gobiernos locales de ese grupo político, aunque, en algunos casos, un ciudadano sin vinculación con el partido puede ocupar una plaza de delegado, siempre que lo solicite al partido político correspondiente y éste apruebe su petición.

A pesar de que en su origen los delegados que formaban las primeras convenciones de los partidos eran elegidos, o bien por el líder del partido, o bien por su comité político (party run caucus system), en la actualidad, los delegados se eligen mediante las elecciones primarias o caucuses, que estamos explicando ${ }^{56}$.

Decidir el número de delegados que le corresponde a cada Estado constituye un proceso muy complejo, y es una tarea que les corresponde exclusivamente a los partidos políticos ${ }^{57}$. Por regla general, se tiene en cuenta la población del Estado así como el apoyo que los ciudadanos de ese Estado han ofrecido a los candidatos del partido en elecciones anteriores ${ }^{58}$.

Por lo que se refiere a la atribución de delegados, es decir, al modo en que se van a asignar a uno o varios de los precandidatos conforme a los resultados de las primarias o caucuses, se siguen procedimientos muy diferentes en función del partido político al que pertenezcan ${ }^{59}$. Así, podemos distinguir dos modelos para adjudicar delegados a cada uno de los precandidatos. Por un lado, en el caso del partido demócrata, se utiliza un sistema proporcional, en el que el porcentaje de votos a favor de un determinado candidato en las elecciones primarias o caucus se refleja en el porcentaje de delegados que representan a ese candidato en la convención. Así, por ejemplo si un Estado tie-

55 L. Bartels, Presidential Primaries, Princeton, Princeton University Press, 1988; A. Busch, "New Features of the 2000 Presidential Nomination Process", en W. MAYER (ed.), In Pursuit of the White House 2000, New York, Chatham House, 2000. S. S. Bowler/T. Donovan/J. Van HeErde, "The United States of America: Perpetual Campaigning in the Absence of Competition", op. cit., pág. 191.

56 K. J. Coleman/J. E. Cantor/T. H. Neale, Presidential Elections in the United States: A Primer, op. cit., pág. 6.

57 Así, en el caso del partido demócrata, se asignan delegados de acuerdo con una fórmula en la que se tienen en cuenta tres factores: la población del Estado, los resultados electorales del partido en ese Estado, y el número de compromisarios que le corresponde a ese Estado en el Colegio Electoral. Por su parte, el partido republicano asigna un número fijo a cada uno de los distritos y Estados, (tres delegados a cada distrito, y otros seis delegados más por Estado), así como un número adicional de delegados, a los Estados que varía en función de los resultados electorales que haya tenido el partido en ese Estado. K. J. Coleman/J. E. Cantor/T. H. Neale, Presidential Elections in the United States: A Primer, op. cit., pág. 8.

58 En las últimas elecciones presidenciales de 2008, el Partido Republicano ha tenido 2.308 delegados, mientras que el Partido Demócrata ha tenido 4.364 delegados.

59 J. Bello/R. Y. Shapiro, "On To the Convention", op. cit., págs. 3 a 6. 
ne 100 delegados y un candidato obtiene el 60\% de los votos en las primarias o caucus, entonces el candidato logra 60 delegados del Estado para la convención nacional. Por otro lado, si se produjera un empate a votos en las elecciones primarias, cada uno de los candidatos del partido obtendría la mitad de los votos de los delegados correspondientes a ese Estado. Por su parte, en el caso del partido republicano, el sistema es diferente, es mayoritario. Los republicanos han optado por el sistema "winner takes all", es decir, el candidato que obtiene la mayoría de los votos es quien consigue todos los delegados de ese Estado. Sin embargo, en algún Estado este partido político ha decidido utilizar el sistema proporcional.

\subsection{Los caucuses}

Existen varias versiones sobre el origen del término caucus. La más probable se remonta al "caucus club" de Boston, de 1765, una asociación de comerciantes y artesanos, una de las primeras asambleas políticas donde se fraguaría la rebelión contra los británicos. Otras interpretaciones se refieren al término indio "caucauasu", un encuentro tribal de jefes, o a la palabra latina "caucus", recipiente.

\subsubsection{Concepto}

El caucus, o asamblea electoral, es una reunión a nivel local en la que los miembros de un partido político de una ciudad, municipio o condado se reúnen para expresar su apoyo a un candidato ${ }^{60}$. El caucus ha sido el sistema tradicional de elección de los candidatos a la presidencia, pero, como hemos visto ya, ha ido perdiendo importancia en favor de las elecciones primarias.

\subsubsection{Procedimiento de celebración}

En los Estados en los que se celebran caucuses, los partidos políticos anuncian la fecha, hora y lugar de celebración de estas asambleas, en las que generalmente participan todos los afiliados y simpatizantes del partido.

El sistema de elección es un sistema "estratificado", lo que supone que primero los activistas locales del partido, actuando en el nivel del distrito, escogen a los delegados que van a asistir al caucus del condado, y éstos, a su vez, seleccionan a los delegados que asistirán a las reuniones estatales. En los caucuses estatales se selecciona a los delegados para la convención nacional de nominación de sus partidos.

60 El sistema es peculiar sobre todo del lado demócrata. Los simpatizantes se reúnen, normalmente en la escuela o la iglesia del pueblo, y votan, a mano alzada, a favor de uno de los candidatos. Todo el proceso dura más o menos una hora. 
En cuanto a la mecánica interna del caucus, tras debatir en el seno de la asamblea, se celebra una votación informal en la que se determina qué delegados se eligen para participar en la convención nacional. No obstante, el sistema de elección en los caucuses difiere en función de las normas de cada Estado y, además, existen ciertas peculiaridades en función del partido político. Así, el sistema de caucus del Partido Republicano es relativamente sencillo. En la reunión se vota, de forma secreta, y en función del porcentaje de votos obtenidos por cada candidato se atribuyen los delegados. Sin embargo, el sistema de elección en el caucus demócrata es mucho más complejo. De hecho, es posiblemente la parte más compleja de todo el proceso de elección presidencial.

En un caucus demócrata típico los afiliados llegan al lugar fijado dentro del distrito electoral para celebrar la asamblea (por ejemplo, en el caso de Iowa, hay cerca de 2.000 caucuses a lo largo del Estado). En la asamblea, los participantes van juntándose formando distintos grupos en función del precandidato al que quieran apoyar ${ }^{61}$. Ahora bien, no se permite que se constituyan tantos grupos como precandidatos, sino que el partido demócrata ha establecido unas reglas muy estrictas para determinar la viabilidad del grupo. Según estas normas, es necesario que el grupo integre un determinado porcentaje de personas respecto del total de los participantes en el caucus. De este modo, si un grupo no tiene suficientes apoyos para ser viable, entonces se disuelve y sus miembros se unen a otro grupo que pueda tener más posibilidades. La determinación de la viabilidad de los grupos, es decir, el porcentaje de participantes que debe lograr un grupo de apoyo a un precandidato, varía en función del número de delegados que le corresponda al distrito electoral en cuestión:

- Si al distrito electoral le corresponde un único delegado, evidentemente no puede utilizarse el sistema proporcional, de modo que el grupo que tenga mayor número de participantes es el que obtiene el voto del delegado.

- Si al distrito electoral le corresponde dos delegados, cada grupo necesita, como mínimo, un 25\% de los participantes en el caucus para optar a la adjudicación de un delegado.

- Si el distrito electoral tiene tres delegados, cada grupo necesita al menos una sexta parte de los participantes del caucus.

- Si el distrito electoral tiene cuatro o más delegados, cada grupo necesita al menos un $15 \%$ de los participantes del caucus.

Una vez que ha quedado definido el número de grupos que pueden constituirse en el caucus de un distrito electoral, el siguiente paso consiste en determinar cuántos delegados le corresponden a cada uno de los grupos. La

61 Además, los seguidores de un determinado precandidato pueden también participar y hacerse oír, incorporándose al grupo de apoyo a su precandidato, sin necesidad de estar afiliado. Es más, los afiliados indecisos también pueden incorporarse a uno de los grupos de su elección. 
fórmula que se utiliza para la asignación es la siguiente: se calcula primero el número de personas que forman parte del grupo, después se multiplica por el número de delegados y la cifra resultante se divide por el total de participantes en el caucus.

Finalmente, hay que indicar que en el caucus los delegados son elegidos para representar los intereses del Estado en la convención nacional del partido, de modo que, en algunos casos, al igual que ocurre en las primarias, estos delegados se comprometen a votar por el precandidato elegido en el caucus, pero, en otras ocasiones, los delegados tienen libertad para votar en la convención al candidato que ellos consideren más adecuado para los intereses del Estado.

\subsection{Las convenciones nacionales de nominación}

Desde su origen, el objetivo principal de las convenciones políticas de los partidos políticos ha sido elegir al candidato del partido a la presidencia. Los partidos políticos celebran convenciones nacionales sólo en los años de elecciones presidenciales. Así, una vez finalizadas las elecciones primarias y los caucuses en los Estados, cada partido celebra una convención nacional para designar oficialmente al candidato que se presentará a la elección presidencial ${ }^{62}$.

La convención nacional está formada por los delegados, que, como ya hemos visto, han sido seleccionados previamente en elecciones primarias y caucuses, y por los denominados superdelegados. Estos últimos son generalmente cargos políticos del Estado que participan también en la Convención para elegir al candidato presidencial, pero que no precisan de una selección previa mediante primarias o caucuses. Los superdelegados son elegidos directamente por los Estados o por los propios partidos políticos. Así, por ejemplo, tienen el status de superdelegado los senadores, diputados y gobernadores del partido ${ }^{63}$.

Los precandidatos que hayan participado en la fase de primarias y caucuses pueden presentarse en la Convención nacional del partido y optar a ser el candidato elegido por ese partido político a la presidencia. Ahora bien, tanto el partido republicano como el demócrata han establecido unos requisitos que deben cumplirse para ello: el partido republicano dispone que el precandidato ha de acreditar que cuenta con el apoyo de los delegados de, al menos, cinco Es-

62 Las Convenciones nacionales de los partidos se suelen celebrar en los meses de verano, principalmente, en julio y agosto. En las últimas elecciones presidenciales de 2008, la Convención Nacional Demócrata se celebró del 25 al 28 de agosto de 2008 en Denver. La Convención Nacional Republicana se celebró del 1 al 4 de septiembre de 2008 en St. Paul, Minnessota.

63 Así, por ejemplo, en el caso del partido demócrata, tienen la consideración de superdelegado: los ex-Presidentes y ex-Vicepresidentes; los líderes (y ex-líderes) y portavoces de los grupos parlamentarios en el Senado y la Cámara de Representantes, todos los presidentes que haya tenido el Comité Nacional Demócrata, los Gobernadores demócratas, los miembros del Comité Nacional, incluidos los presidentes y vicepresidentes de los comités estatales del Partido, y todos los miembros demócratas del Senado y de la Cámara de Representantes. K. J. Coleman/J. E. Cantor/T. H. Neale, Presidential Elections in the United States: A Primer, op. cit., pág. 9. 
tados, para poder optar a la nominación; por su parte, el partido demócrata establece que los precandidatos han de presentar al menos el apoyo de 50 delegados, de los cuales no más de veinte pueden ser del mismo Estado ${ }^{64}$.

En principio, en el procedimiento de votación, los delegados deben votar por el candidato al que representan. Ahora bien, es habitual que durante el proceso electoral, algunos de los precandidatos que han ganado elecciones primarias estatales no continúen en la contienda electoral. En esos casos, pueden darse dos posibilidades: la primera, que el candidato que se retire anuncie públicamente su apoyo a otro candidato, en cuyo caso los delegados votarán por ese candidato; y, la segunda, que se dé libertad de voto a los delegados. Por su parte, los superdelegados pueden decidir libremente su voto, aunque en ocasiones, pueden prometer su apoyo previamente a un determinado candidato ${ }^{65}$.

En la votación que se realiza en la Convención para elegir al candidato puede darse el caso de que en un primer recuento ningún candidato obtenga la mayoría de votos exigida. En ese supuesto, se permite a los delegados cambiar su voto en una segunda votación.

Finalizadas las votaciones, el candidato elegido es aquél que tiene el apoyo de la mayoría de los delegados y superdelegados que participan en la convención. Y, normalmente, el candidato a la presidencia elige entonces al candidato a la vicepresidencia, que se presentará a las elecciones presidenciales junto a él.

Cabe resaltar que en la actualidad es habitual que ya se conozca el nombre del candidato con anterioridad a la celebración de la convención, con lo que la relevancia de ésta, en sentido estricto, es menor. Sin embargo, desde el punto de vista mediático y político, la celebración de las convenciones nacionales constituye uno de los momentos más importantes de la campaña, aunque ya se conozca de antemano la identidad del candidato a la presidencia. Además, las convenciones políticas sirven para algo más que para elegir al candidato a la presidencia, pues ofrecen a los miembros del partido la posibilidad de discutir y aprobar el programa electoral, así como de fijar los objetivos de la campaña presidencial ${ }^{66}$.

\section{LA ELECCIÓN DEL PRESIDENTE}

Una vez concluida la fase previa de elección del candidato a la presidencia por cada uno de los partidos políticos es cuando comienza el proceso de elecciones presidenciales.

64 K. J. Coleman/J. E. Cantor/T. H. Neale, Presidential Elections in the United States: A Primer, op. cit., pág. 19.

65 En el último proceso electoral de 2008, los demócratas han tenido 800 superdelegados, una cifra muy importante, teniendo en cuenta que para lograr la nominación era suficiente con lograr 2.183 votos a favor. J. Bello/R. Y. ShAPIRo, "On To the Convention", op. cit., pág. 8.

66 J. W. Davis, National Conventions in an Age of Party Reform, op. cit., pág. 43 y ss. 
El procedimiento para elegir al Presidente de los Estados Unidos consta de dos fases: en primer lugar, la jornada electoral, en la que todos los ciudadanos ejercen su derecho de voto; y, en segundo lugar, la elección formal del Presidente que la realiza el Colegio Electoral.

\section{LA JORNADA ELECTORAL}

El primer martes de noviembre se celebra la jornada electoral, en la que sólo participan los candidatos elegidos por los partidos políticos. La fecha de celebración de las elecciones presidenciales es la misma en todo el territorio. Pero ése es el único aspecto en el que coinciden todos los Estados, en el día de celebración de las elecciones presidenciales ${ }^{67}$. En todo lo demás, los Estados son libres para determinar la manera de participación en las elecciones y de emisión del voto. Así, por ejemplo, los Estados son quienes fijan los requisitos que hay que cumplir para poder votar (si el ciudadano debe registrarse en el censo electoral para ello, si se necesitan ciertos requisitos de residencia, etc.), los que fijan el procedimiento para el voto por correo $^{68}$, los que fijan el método para votar, es decir, si se utilizan papeletas, de qué tipo, si utilizan medios electrónicos o telemáticos para emitir el voto, etc... ${ }^{69}$. Como resultado de ello, las jornadas electorales en cada uno de los Estados

67 Aunque constitucionalmente no se dispone nada sobre la fecha de celebración de las elecciones presidenciales, más allá de que han de celebrarse cada cuatro años, es el Congreso el encargado de fijar por ley federal las fechas de celebración de todas las elecciones federales (elecciones presidenciales, al Senado y a la Cámara de Representantes). En concreto, den 1845 se acordó que las elecciones presidenciales se celebran el primer martes posterior al primer lunes del mes de noviembre, cada cuatro años (5 Stat. 721). K. J. Coleman/J. E. Cantor/T. H. Neale, Presidential Elections in the United States: A Primer, op. cit., pág. 38.

68 Lo que nosotros denominamos voto por correo tiene una consideración más amplia en los Estados Unidos. Allí se denomina voto ausente, y se considera como tal a todo el voto que no se pueda emitir directamente durante la jornada electoral. Así, los ciudadanos norteamericanos, que, por los motivos que sean, no puedan ejercer su derecho al voto en el día de la elección, pueden formular su solicitud de voto ausente, y votan mediante el sistema que su Estado haya habilitado al efecto (voto anticipado, voto por correo, voto por otros medios telemáticos, etc.). Todos los Estados establecen medidas para permitir el voto ausente, aunque algunos de ellos limitan esta posibilidad únicamente a supuestos muy concretos. Sobre este aspecto, se han producido ciertos problemas de aplicación práctica y de cómputo real de los votos. Así, en las elecciones presidenciales de 1960, en el Estado de California, debido a un recuento tardío de estos votos se adjudicaron los compromisarios a Richard Nixon en lugar de a John F. Kennedy. Vid, en este sentido, J. C. Plano/M. Greenberg, The American Political Dictionary, op. cit., pág. 113.

69 Esta variedad de modalidades ha recibido numerosas críticas, sobre todo, por la poca fiabilidad de los sistemas utilizados en algunos Estados. Prueba de ello fue el escándalo en las elecciones 2000 con las conocidas "papeletas mariposa", muchas de las cuales no se tuvieron en cuenta a la hora de hacer el recuento al no quedar claro a quién iba destinado el voto, pues la máquina encargada de verificarlo no funcionó correctamente. Esto derivó en una impugnación del proceso electoral por parte del candidato Al Gore, que acabó en el Tribunal Supremo (Sentencia Bush v. Gore, 531 US 98, 104, (2000)). 
son realmente diferentes entre sí. Por ejemplo, en lo relativo a los requisitos para poder ejercer el derecho de sufragio, ciertos Estados establecen normas muy estrictas y rigurosas para que los ciudadanos puedan inscribirse en el censo electoral y, por tanto, puedan votar (como, por ejemplo, acreditar un tiempo previo de residencia), mientras que otros apenas regulan esta cuestión; respecto de la duración de la jornada electoral, ésta tiene una duración entre siete y catorce horas, dependiendo del Estado y del distrito electoral ${ }^{70}$. En lo relativo al voto por correo, algunos Estados son extremadamente flexibles en este aspecto, hasta el punto de que admiten que se pueda votar por email o por fax (sin verificar, por tanto, la identidad del votante) ${ }^{71}$, mientras que otros limitan el voto por correo única y exclusivamente a los miembros de las fuerzas armadas estadounidense que se encuentren en el extranjero. Por lo que se refiere a la forma de emisión del voto, igualmente nos encontramos con muchas diferencias entre los Estados, que establecen procedimientos muy dispares, que abarcan desde la papeleta tradicional al voto electrónico. Ante esta situación tan heterogénea, el Tribunal Supremo ha recomendado cierta homogeneidad en estas cuestiones, pero sin éxito. A día de hoy, siguen existiendo procedimientos muy dispares en los Estados a la hora de votar ${ }^{72}$.

Lo que debemos destacar aquí es que en la jornada electoral, los ciudadanos realizan una doble votación, ya que votan, por un lado, a uno de los candidatos a Presidente (lo que se conoce como "voto popular"), y, por otro, votan a la lista de los compromisarios electorales del mismo partido que el candidato elegido, que integrarán el Colegio Electoral ${ }^{73}$. En ambos casos, el sistema electoral es de tipo mayoritario, a excepción de dos Estados - Maine y Nebraska - por lo que el candidato que obtenga la mayoría de los votos se convierte en vencedor del Estado y a la lista de compromisarios de su partido político, que será también la más votada, se le adjudican todos los votos electorales de ese Estado (winner takes all) ${ }^{74}$. Esto es, si a un Estado le corresponden 20 compromisarios en el Colegio Electoral, el candidato a Presidente que obtenga la mayoría en dicho Estado obtiene así para su partido político los 20 compromisarios del mismo.

70 VVAA, The Book of the States, 1998-99 Edition, The Council of State Governments, Lexington, KY, 1998, pág. 163.

71 Por ejemplo, el Estado de California ha permitido votar por fax o incluso por email a sus ciudadanos en las últimas elecciones presidenciales de 2008

72 Sentencia Bush v. Gore, 531 US 98, 104, (2000).

73 S. Bowler/T. Donovan/J. Van Heerde, "The United States of America: Perpetual Campaigning in the Absence of Competition", op. cit., págs. 191 y 192; L. LONGLEY/N. PIERCE, The Electoral College Primer 2000.

74 Sólo dos Estados no siguen esta regla de "winner takes all", Maine y Nebraska, que utilizan el denominado "district system". En estos Estados dos compromisarios los logra el candidato que haya logrado el mayor número de votos, el compromisario restante en el caso de Maine, y los dos restantes en el caso de Nebraska, se adjudican a la candidatura que haya obtenido una mayoría de votos en todos los distritos electorales. 


\section{La elección del Presidente: el Colegio Electoral}

De acuerdo con la Constitución, la elección del Presidente se encomienda al Colegio Electoral, que es un órgano formado por 538 compromisarios que representan a los cincuenta Estados y al Distrito de Columbia. El número de compromisarios que corresponde a cada uno de los Estados se fija en función de la población de cada uno de ellos y coincide con el número de Senadores y Diputados que tiene cada Estado ${ }^{75}$. Los compromisarios son elegidos por los partidos según el procedimiento que se determine a nivel estatal ${ }^{76}$, aunque, en todo caso, quedan excluidos los diputados, los senadores y los funcionarios federales ${ }^{77}$. De este modo, cada uno de los partidos políticos que se presenta a las elecciones debe presentar no sólo a sus candidatos a Presidente y Vicepresidente, sino también una lista con los candidatos a compromisarios en cada uno de los Estados ${ }^{78}$.

Una vez celebrada la elección popular, se procede a la elección formal del Presidente y el Vicepresidente en el Colegio Electoral. Así, los compromisarios se reúnen en la capital de su respectivo Estado en el mes de diciembre posterior a la elección, en concreto, el tercer lunes de diciembre, y emiten sus votos para Presidente y Vicepresidente ${ }^{79}$. Los votos electorales de los compromisarios se envían entonces a Washington, donde se suman to-

75. Los votos electorales (compromisarios) que le corresponde a cada uno de los Estados son: Alabama, 9; Alaska, 3; Arizona, 10; Arkansas, 6; California, 55; Carolina del Norte, 15; Carolina del Sur, 8; Colorado, 9; Connecticut, 7; Dakota del Norte, 3; Dakota del Sur, 3; Delaware, 3; Florida, 27; Georgia, 15; Hawai, 4; Idaho, 4; Illinois, 21; Indiana, 11; Iowa, 7; Kansas, 6; Kentucky, 8; Louisiana, 9; Maine, 4; Maryland, 10; Massachussets, 12; Michigan, 17; Minnesota, 10; Missisippi, 6; Missouri, 11; Montana, 3; Nebraska, 5; Nevada, 5; New Hampshire, 4; New Jersey, 15; Nueva York, 31; Nuevo México, 5; Ohio, 20; Oklahoma, 7; Oregón, 7; Pennsylvania, 21; Rhode Island, 4; Tennessee, 11; Texas, 34; Utah, 5; Vermont, 3; Virginia, 13; Washington, 11; West Virginia, 5; Wisconsin, 10; Wyoming, 3; y el Distrito de Columbia, 3.

76 En las primeras elecciones presidenciales, existían diferencias entre los Estados en relación con la forma de elegir a los compromisarios. Así, en algunos Estados, eran los propios órganos legislativos del Estado los encargados de elegir a los compromisarios, mientras que en otros Estados la elección le correspondía al cuerpo electoral. Esta segunda opción se generalizó rápidamente y es la que se viene utilizando en la actualidad. T. H. NEale, The Electoral College: How it Works in Contemporary Presidential Elections, op. cit., pág. 3; W. KimberLing, The Electoral College, págs. 2 a 10.

77 Constitución de los Estados Unidos, artículo II, sección I, \2.

78 Es habitual que los partidos políticos elijan a los compromisarios electorales en las convenciones nacionales de los partidos, aunque, en ocasiones, los compromisarios son elegidos por los comités estatales de los partidos. K. J. Coleman/J. E. Cantor/T. H. Neale, Presidential Elections in the United States: A Primer, op. cit., pág. 42.

79 Los partidos políticos se encargan de controlar que el voto de los compromisarios vaya a la candidatura presidencial del partido al que representan. En este sentido, el Tribunal Supremo consideró que no es inconstitucional la exigencia de los partidos de una declaración previa a favor de sus candidatos a la presidencia y vicepresidencia como condición para ser propuesto como candidato a compromisario (Sentencia Ray v. Blair, de 1952). N. Pierce/L. D. Longley, The People's President: The Electoral College in American History and the Direct Vote Alternative, rev. ed., New Haven, CT, Yale U. Press, 1991, págs. 96-101. 
dos los votos electorales por Estado, en una sesión conjunta del Senado y la Cámara de Representantes que se celebra en el mes de enero ${ }^{80}$. La Constitución establece que el candidato que obtenga el apoyo de la mayoría absoluta de los compromisarios ( 270 votos), se alza con la Presidencia y el que obtenga mayor número de votos a continuación será nombrado vicepresidente $^{81}$.

En el caso de que ninguno de los candidatos a la Presidencia obtuviera la mayoría absoluta requerida, la Constitución dispone que la Cámara de Representantes será la encargada de elegir al Presidente de entre los tres candidatos que hayan obtenido mayor número de votos. En este caso, se asigna un solo voto a cada Estado, así como al Distrito de Columbia, y se procede a una nueva votación ${ }^{82}$.

Una de las críticas que ha recibido este sistema de elección indirecta es que hace posible la existencia de Presidentes minoritarios. Se denomina así a los Presidentes que resultan elegidos por la mayoría absoluta de los votos de los compromisarios, pero sin que estos, a su vez, supongan la mayoría del voto popular. Es decir, puede darse el caso, y, de hecho, se ha dado esa circunstancia en varias ocasiones, que el candidato que haya ganado el voto popular (mayoría en el número de votos emitidos por los ciudadanos) no haya logrado ser investido Presidente de los Estados Unidos, al no lograr la mayoría de los votos de los compromisarios ${ }^{83}$.

\section{LA CAMPAÑA ELECTORAL}

Para concluir este estudio, haremos referencia brevemente a la campaña electoral que tiene lugar a lo largo de todo el proceso hasta aquí descrito, y, más concretamente, a la financiación y el acceso a los medios de comunicación, que son las únicas materias que tienen una regulación federal, pues, como ya hemos visto, el resto del proceso electoral lo regulan los legisladores estatales.

803 U.S.C. $\int$ 8. T. H. Neale, The Electoral College: How it Works in Contemporary Presidential Elections, op. cit., pág. 5.

81 La XII Enmienda a la Constitución estadounidense obliga a los compromisarios a especificar en cada una de sus dos papeletas de voto el candidato a presidente y a vicepresidente que eligen.

82 Constitución, XII Enmienda. En dos ocasiones la Cámara de Representantes ha tenido que elegir al Presidente y Vicepresidente, al no haberse logrado la mayoría suficiente en el Colegio Electoral. CRS, Election of the President and Vice President by Congress: Contingent Election.

83 De hecho, en diecisiete elecciones presidenciales el ganador no obtuvo la mayoría del voto popular. La primera vez que ocurrió fue en las elecciones de 1824, cuando resultó ganador John Quincy Adams, y la última, en las elecciones presidenciales de 2000, en las que resultó ganador George W. Bush, aunque el vencedor en el voto popular fue Al Gore. D. LONGLEY, The People's President, New Haven, Yale University Press, 1981, págs. 241 y ss.. 


\section{FinANCIACiÓN DE LA CAMPAÑa ELECTORAL}

La financiación de la campaña electoral para las elecciones federales, esto es, para las elecciones presidenciales y al Congreso de los Estados Unidos - Cámara de Representantes y Senado - se regula en la Federal Election Campaign Act (en adelante, FECA) ${ }^{84}$.

La financiación de la campaña electoral en los Estados Unidos tiene dos rasgos esenciales. El primero, que las normas que regulan la financiación de la campaña se aplican principalmente a los candidatos y no a los partidos políticos a los que éstos pertenecen ${ }^{85}$, y el segundo, que, a pesar de que se establecen, como vamos a ver, fuentes de financiación pública y privada, son éstas últimas las que constituyen la principal fuente de ingresos de los candidatos, si no la única ${ }^{86}$.

A tenor de lo dispuesto en la Ley, existen dos tipos de financiación de la campaña electoral: la financiación pública y la financiación privada.

\subsection{Financiación pública}

Las elecciones presidenciales son las únicas elecciones federales que cuentan con financiación pública ${ }^{87}$. En este sentido, los candidatos a la presidencia reciben fondos del gobierno federal para cubrir parte de los gastos de sus campañas electorales, tanto en la fase previa de prenominación (en las elecciones primarias y caucuses) como en las presidenciales, y los partidos políticos reciben fondos federales para la celebración de las convenciones nacionales en las que se procede a la elección de los candidatos del partido a la presidencia ${ }^{88}$.

Sin embargo, para poder obtener fondos públicos, los candidatos presidenciales y los comités de los partidos políticos que preparan las con-

84 Federal Election Campaign Act de 1971 (Pub. L. No. 92-225, 86 Stat. 3). El resto de los procesos electorales, ya sean estatales o locales, se rigen por sus propias normas electorales, aunque la FECA actúa con carácter supletorio. FECA, sección 453.

85 En los Estados Unidos, los partidos políticos, por su propia naturaleza y por su peculiar sistema político, tienen una importancia relativa, mientras que los verdaderamente importantes son los candidatos. Por ello, todas las normas que a lo largo de la historia de este país han regulado la financiación de la campaña electoral, ya desde el siglo XIX, se han ocupado principalmente de fijar las reglas que debían cumplir los candidatos, no los partidos.

86 K.-H. Nassmacher, "Party funding in Continental Western Europe", en VVAA, Funding of Political Parties and Election Campaigns, 2003, pág. 33; S. SánCHEZ GonZÁlez, "La financiación de los partidos políticos en los Estados Unidos", en Teoría y Realidad Constitucional, n. 6, 2000, págs. 72-73.

87 FECA, Internal Revenue Code, Presidential Election Campaign Fund Act, sección 9001 y ss.

88 FEC, Financiación pública de las elecciones presidenciales, 1994. L.H. TriBE, American Constitutional Law, op. cit., pág. 1148 y ss. 
venciones nacionales deben cumplir con varios requisitos legales, el más importante, someterse a los límites de gastos electorales que señala la Ley ${ }^{89}$.

El Departamento del Tesoro de los Estados Unidos crea el Fondo de Campaña para las Elecciones Presidenciales (Presidential Election Campaign Fund), fondo con el que se van haciendo los pagos correspondientes a los candidatos y partidos políticos que cumplen con los requisitos y condiciones legales ${ }^{90}$. Este Fondo de Campaña para las Elecciones Presidenciales se distribuye conforme a tres programas: desembolsos paralelos para las elecciones primarias (Presidential Primary Matching Payment Account), subvenciones para la celebración de las convenciones nacionales de los partidos (Payments for presidential nominating conventions), y subvenciones para las elecciones generales (Presidential Election Campaign Fund).

El programa de desembolsos paralelos para las elecciones primarias (Presidential Primary Matching Payment Account) consiste en lo siguiente: los precandidatos que participan en las elecciones presidenciales primarias y que reúnan las condiciones legalmente establecidas, pueden recibir los fondos públicos denominados "desembolsos paralelos" (matching funds) ${ }^{91}$. De este modo, por cada $2.000 \$$ que reciba el precandidato por donaciones individuales, el Estado le concederá 250 \$ en concepto de "desembolso paralelo" (matching fund $)^{92}$. Ahora bien, para poder obtener estos fondos públicos, el precandidato se compromete a utilizar los fondos públicos única y exclusivamente para cubrir los gastos de campaña y, además, lo más importante, deben someterse a un límite máximo de gastos durante la campaña electoral fijado en la Ley $^{93}$. Por ello, la mayoría de los precandidatos renuncian a los desembolsos paralelos, para no someterse a ningún tipo de límite en los gastos electorales ${ }^{94}$.

El segundo de los programas de financiación pública consiste en subvencionar la celebración de las convenciones nacionales de los partidos en las que cada uno de los partidos políticos elige a sus candidatos a la presidencia

89 A tenor de lo que establece la FECA en su sección 441.a.(b), ningún candidato a la presidencia de los Estados Unidos puede ingresar más de 10 millones de dólares durante las elecciones primarias, es decir, en la campaña para ser elegido el candidato a la presidencia por su partido, y otros 20 millones de dólares en la campaña para la presidencia.

90 Este fondo se integra exclusivamente por la donación tributaria de 3 \$ (o hasta 6 \$ por declaración conjunta) que cada contribuyente haga voluntariamente al marcar la correspondiente casilla en su declaración de impuestos. FECA, sección 6096.

91 FECA, sección 9033.

92 FECA, sección 9034.

93 La FECA dispone como límite máximo de gasto para las elecciones primarias de los precandidatos, la cantidad de 10 millones de dólares. FECA, sección 441.1. (b) (1) (A). Hay que tener en cuenta que las cantidades que aparecen en la FECA han ido incrementándose de acuerdo con el IPC. Así, en las últimas elecciones presidenciales de 2008, el límite gasto en la fase de primarias ha sido de 50,46 millones de dólares. http://www.fec.gov.

94 Así, de los 147 precandidatos que se registraron en la FEC en las últimas elecciones presidenciales, sólo ocho de ellos solicitaron desembolsos paralelos. http://www.fec.gov. 
y vicepresidencia de los Estados Unidos (Payments for presidential nominating conventions $)^{95}$. La Ley establece que tienen derecho a estas subvenciones los partidos políticos mayoritarios y todos los partidos políticos que hayan obtenido al menos un 5\% de los votos en las elecciones presidenciales anteriores, aunque las cantidades que se conceden a unos y a otros son diferentes ${ }^{96}$. En este sentido, los partidos políticos mayoritarios reciben la cantidad de 4 millones de dólares para la celebración de la convención, mientras que los partidos políticos minoritarios obtienen una cantidad inferior proporcional al número de votos que haya obtenido su candidato en las anteriores elecciones presidenciales $^{97}$. La FECA establece además que el comité encargado de organizar la convención nacional para elegir al candidato a la presidencia del partido no puede efectuar gastos por un importe superior a la subvención recibida, aunque de esta previsión legal se excluyen ciertas actividades y servi$\operatorname{cios}^{98}$.

El tercer programa de financiación pública que establece la FECA consiste en que los candidatos a la presidencia de los Estados Unidos pueden solicitar subvenciones para financiar su campaña electoral durante las elecciones presidenciales, mediante el Fondo para la Campaña en Elecciones Presidenciales (Presidential Election Campaign Fund) ${ }^{99}$. De acuerdo con la Ley, se establecen diferentes sistemas de asignación de las subvenciones dependiendo si se trata de candidatos de los partidos mayoritarios o de los minoritarios. Por lo que a los partidos mayoritarios se refiere, los candidatos a la presidencia de los Estados Unidos de los partidos demócrata y republicano tienen derecho a recibir una subvención para cubrir todos los gastos de su campaña ${ }^{100}$. Ahora bien, para poder obtener dicha subvención, el candidato se comprometer a no superar el límite de gastos legalmente establecido así como a no recaudar otros ingresos. Es decir, sólo podrán utilizar los fondos públicos asignados para su campaña y no podrá obtener ningún otro tipo de recursos. Por lo que se refiere a los partidos minoritarios o de nueva creación, sus candidatos también pueden acceder a subvenciones públicas, pero en condiciones muy di-

95 FECA, sección 9008

96 A efectos de la FECA, son partidos mayoritarios aquellos que hubieran obtenido más del 25\% de los votos en las elecciones anteriores. FECA, sección 9002 (6).

97 FECA, sección 9008 (b). La cantidad de 4 millones de dólares se ha ido incrementando ajustándolo al índice de precios el consumo. Para las elecciones presidenciales de 2008, la FEC ha dispuesto que los dos partidos políticos mayoritarios recibirán la cantidad de \$16.820.760 cada uno.

98 Por ejemplo, que la ciudad donde se celebre la convención provea de transporte gratuito, etc.

99 En este sentido, la FECA define a los partidos mayoritarios como los partidos que, en las elecciones anteriores hubieran obtenido más del 25\% de los votos. FECA, sección 9002 (6).

100 De acuerdo con la redacción original de la FECA, la subvención básica es de 20 millones de dólares, pero esta cifra se incrementa todos los años conforme a la inflación. FECA, sección 9003 (b), sección 9004 (a) (1); y sección 441 (1) (b) (1) (B). Así, en las últimas elecciones presidenciales de 2008, la cantidad destinada a los candidatos mayoritarios en este fondo ascendía a $\$ 84.103 .800$. 
ferentes; así, el candidato presidencial de un tercer partido tiene derecho a financiación pública, una vez hayan concluido las elecciones presidenciales y siempre y cuando haya obtenido, al menos, el 5\% de los votos. La cantidad que reciben los candidatos minoritarios se calcula teniendo en cuenta los votos obtenidos en las elecciones presidenciales y el promedio de votos obtenidos por los dos candidatos de los partidos mayoritarios. En el caso de un partido nuevo, la cantidad se calcula teniendo en cuenta la proporción de votos del candidato del nuevo partido en relación con el promedio de votos de los candidatos de los dos partidos mayoritarios en la elección. Para compensar el trato desigual que se da a los partidos minoritarios respecto de los mayoritarios, la Ley establece que los candidatos de un partido minoritario o de un nuevo partido pueden complementar los fondos públicos con donaciones privadas siempre que los ingresos totales no superen el límite de gastos legalmente establecido ${ }^{101}$.

En la práctica, a los partidos políticos mayoritarios no les interesa aceptar las subvenciones públicas, ya que no les compensa someterse al límite del gasto marcado legalmente para recibir las subvenciones públicas. Por eso, en las últimas convocatorias electorales estos partidos han renunciado a las mismas. Las cifras de las últimas elecciones presidenciales lo demuestran con toda rotundidad ${ }^{102}$.

\subsection{Financiación privada}

En la práctica, las fuentes de financiación privada constituyen la única fuente de ingresos de los candidatos en las elecciones presidenciales. En este sentido, podemos distinguir cuatro tipos de financiación privada: las cuotas de los afiliados a los partidos políticos, que es una fuente de ingresos menor ${ }^{103}$; las donaciones a los candidatos o a partidos, que constituyen la principal fuente de ingresos; los fondos personales del candidato; y los denominados "gastos independientes" - literalmente independent expenditu-

101 FECA, sección 9003 (c).

102 En las últimas elecciones presidenciales de 2008, se ha superado el billón de dólares en gastos electorales. Así, por ejemplo, el candidato demócrata Barack Obama recaudó 770.506.083 millones de dólares, y el candidato republicano, John McCain recaudó 383.912.824 millones de dólares. Hay que indicar además, que en un estudio realizado por el Center for Responsible Politics, se afirma que en 9 de cada 10 casos, el candidato que gasta más dinero consigue ser elegido.

103 Las cuotas de los afiliados son las cantidades que ingresa un partido político o un candidato por suscripciones regulares de los miembros del partido. Hay que señalar que en la tradición anglosajona no es habitual la existencia de un número elevado de afiliados a un partido político, por lo que la contribución que éstos hacen a la suma total de ingresos no es muy alta. K.-H. Nassmacher, "The funding of political parties in the Anglo-saxon orbit", op. cit., pág. 36. 
res_ ${ }^{104}$, que forman parte del "soft money", y con los que se sufragan buena parte de los gastos de la campaña electoral ${ }^{105}$.

Las donaciones son la principal fuente de ingresos de que disponen los candidatos electorales y los partidos políticos. En este sentido, la FECA dispone que cualquier ciudadano puede realizar donaciones, ya sean tanto económicas como donaciones en especie (prestación de servicios, etc.), aunque esta Ley también establece límites y prohibiciones, que expondremos brevemente ${ }^{106}$.

De acuerdo con la Ley, existen distintos tipos de donaciones, en función de quién realice la donación y a quién va destinada la misma ${ }^{107}$. Con carácter general, cualquier ciudadano puede entregar determinadas cantidades económicas o realizar determinadas prestaciones en concepto de donación a un partido político o a un candidato electoral siempre que dichas donaciones se

104 Se entiende por "gasto independiente" todo desembolso que realizan dichas personas particulares para costear actividades de propaganda electoral a favor o en contra de un determinado candidato y que se hace independientemente de la campaña del candidato. Así, por ejemplo, se consideran gastos de ese tipo la publicación en un periódico de un anuncio pidiendo el voto por un determinado candidato. Hay que señalar que la Ley exige que en estos casos se publique una nota en el anuncio publicitario aclarando quién ha pagado por ella y que ésta no ha sido autorizada por ningún candidato (es decir, que es «independiente»). FECA, sección 431 (17).

105 Es preciso señalar que tanto la FECA como el Tribunal Supremo han diferenciado dos tipos de fuentes de financiación privada: las que se denominan "hard money", que son las cuotas de los afiliados y las donaciones, que se entregan directamente al candidato electoral, al partido, o al comité electoral del candidato, y que están sujetas a la fiscalización de la FEC; y, por otro lado, las fuentes de financiación que se denominan "soft money", que son los fondos personales y los "gastos independientes", que se destinan también a la financiación de un candidato electoral, pero de manera indirecta, pues o bien consisten en la financiación directa de determinadas actividades de campaña o bien constituyen el patrimonio personal del propio candidato, y lo que ambas formas de financiación tienen en común es que escapan, en ocasiones, al control de la FEC. En la doctrina, vid., O.T. Stephens JR./J. M. Scheb II, American Constitutional Law, 3. ${ }^{a}$ ed., 2003, pág. 815; VVAA, "Recent legislation: Campaign Finance Reform", en 114 Harvard Law Review (2000), pág. 2209; A. B. Kratenstein, "Recent legislation: Campaign Finance Reform", en 36 Harvard Journal on Legislation 219, 221, 222 (1999); y E.J. DionnE JR., "Money and Elections", en The Washington Post, de 9 de abril de 2004, pág. 8.

106 La FECA ha prohibido expresamente que cierto tipo de personas físicas o jurídicas puedan realizar donaciones en los procesos electorales federales. Así, los extranjeros, los sindicatos de trabajadores, los contratistas del gobierno federal o las empresas, tienen prohibido efectuar donaciones. FECA, sección 441.b.(a). Sin embargo, paradójicamente, las empresas o los sindicatos, pueden financiar indirectamente a los candidatos a través de la creación de los denominados "COmités de acción política", que son organizaciones reconocidas por la Ley que tienen como objetivo respaldar y apoyar, también económicamente, a los candidatos y partidos políticos. Por lo tanto, cualquier empresa que quiera financiar a un candidato lo que hace es constituir un comité de acción política de apoyo a ese candidato. FECA, sección 441.a (5). R. J. HrebenAR/M. J. BuRBANK/R. C. BENEDICT, Political Parties, Interest Groups, and Political Campaigns, 1999.

107 Así, la FECA distingue, por lo que se refiere a quién puede efectuar donaciones, entre las donaciones individuales, las donaciones de los comités electorales de los partidos y las donaciones de los comités de acción política. Por otro lado, y en relación a quién recibe la donación, la Ley distingue entre las donaciones a los candidatos (tanto en la fase de primarias como en la fase de elección presidencial), las donaciones a los comités electorales de los partidos y las donaciones a los comités de acción política. 
ajusten a los diferentes límites que la Ley establece ${ }^{108}$. Más en concreto, y por lo que se refiere a las donaciones que pueden recibir los candidatos en las elecciones presidenciales, la FECA dispone que todos los precandidatos que se presenten a las elecciones pueden recibir un máximo de $2.000 \$$ por persona, durante la fase de las elecciones primarias, con independencia de si el precandidato obtiene o no financiación pública ${ }^{109}$. Además, una vez finalizada la fase de prenominación, y elegidos los candidatos a la presidencia por parte de cada uno de los partidos políticos, éstos pueden obtener otros 2.000 $\$$ por persona para sufragar los gastos de su campaña electoral, siempre y cuando no hayan solicitado financiación pública ${ }^{110}$.

\section{El ACCESO DE los CANDidatos A los MEDiOS DE COMUNICACiÓN}

El acceso a los medios de comunicación de los distintos candidatos durante las elecciones presidenciales se regula en la Communications Act de $1934^{111}$, y muestra importantes diferencias con los sistemas europeos. La diferencia más destacable es que en los Estados Unidos no existen espacios gratuitos de propaganda electoral, sino que los candidatos y los partidos políticos de acuerdo con su capacidad económica, difunden sus mensajes de propaganda electoral adquiriendo espacios de publicidad en los medios de comunicación, con la única obligación para las radios y televisiones de respetar las previsiones establecidas en la Communications Act, en concreto, las reglas del "acceso razonable" y del "equal time rule" ${ }^{112}$.

En este sentido, la sección 312 de la Communications Act, establece que los candidatos tienen derecho de acceso a los medios de radiodifusión en el sentido de que los medios deben ofrecer "razonables" $\mathrm{y}$ "adecuados" espacios de difusión a todos los candidatos que participan en la competición política. Esta previsión de la Ley se completa con la sección 315 de la Communications Act, que reconoce la "equal time rule", que significa que todo medio

108 Así, la Ley establece, con carácter general, que los ciudadanos no pueden superar los siguientes límites: en primer lugar, 37.500 \$ por año civil en concepto de donaciones directas a los candidatos o donaciones indirectas a través de los comités electorales de los candidatos; en segundo lugar, 57.500 \$ para el resto de donaciones, de las cuales únicamente 37.500 \$ podrán ser destinados a los Comités de acción política o a los comités electorales estatales o locales. Además de estos límites generales, la Ley también establece otros límites específicos según el destinatario de la donación. FECA, sección 441.a; Instrucciones de la FEC de 27 de enero de 2003 (11 CFR, Part. 100, 101, 104, 110, 116, 400 y 9035)

109 FECA, sección 441.a.(a).

110 FECA, sección 9002.

111 47, U.S.C.

112 La doctrina ha sido muy crítica, ya que considera que los candidatos con más recursos económicos se benefician de este sistema; y, en consecuencia, tienen más posibilidades de lograr el éxito electoral. Vid., L. H. Tribe, American Constitutional Law, op. cit., pág. 1129; K. R. MiDDLeton/B. F. Chamberlain/M. D. Bunker, The Law of public communication, Longman Ed., 1997, pág. 536; F. Rowan, Broadcast Fairness, Doctrine, Practice, Prospects. A Reappraisal of the Fairness Doctrine and Equal Time Rule, 1984, pág. xii; W. J. M. MACKEnZIE, Free Elections, 1958, pág. 166. 
de comunicación que hubiera ofrecido tiempo en su programación a un candidato, tiene que hacer lo mismo con los demás candidatos que concurren a las elecciones, excepto en los programas que tengan la consideración de "programas informativos de interés general", que no han de cumplir con esta exigencia ${ }^{113}$. Además de estas dos normas, también se establecen medidas legales para evitar la censura de los mensajes de los candidatos y la imposición de unas tarifas especiales para los spots electorales ${ }^{114}$.

Por otro lado, es preciso indicar aquí que, a diferencia de lo que ocurre en la mayoría de los sistemas electorales europeos, en los Estados Unidos no existe un periodo de tiempo calificado expresamente como campaña electoral, con unas garantías o requisitos especiales y, por lo tanto, legalmente tampoco existe ningún límite temporal para las actividades de campaña de los partidos políticos, ya sea para la emisión de espacios electorales, que pueden comenzar a emitir cuando lo consideren más conveniente para su estrategia política, como para la puesta en marcha de cualquier otra actividad de campaña ${ }^{115}$. Sin embargo, la Ley sí establece dos periodos de tiempo en los que los medios de comunicación tienen que cumplir con las obligaciones de reconocer un "acceso razonable" y la "equal time rule", que son los siguientes: treinta días antes de la celebración de las elecciones primarias y sesenta días antes de la celebración de las elecciones presidenciales ${ }^{116}$.

De acuerdo con la Communications Act, tienen derecho a adquirir espacios de publicidad electoral todos los candidatos que participan en las elecciones presidenciales ${ }^{117}$, es decir, todo candidato que haya hecho pública su intención de presentarse a las elecciones, y que cumple con los requisitos legalmente establecidos por la legislación estatal o federal ${ }^{118}$. En este sentido, se ha insistido

113 Paradójicamente, de acuerdo con la Communications Act, tienen la consideración de "programas informativos de interés general", y, por tanto, quedan exentos de cumplir con estas reglas, los informativos o programas de noticias, los debates electorales, las entrevistas a los candidatos electorales o cualquier otro programa especial dedicado a ofrecer información sobre la campaña electoral. Sí se aplican esas normas, por el contrario, a otros programas, como, por ejemplo, programas deportivos, de entretenimiento, comedias de situación o películas.

114 J. Z. Zelezny, Communications Law, Liberties, Restraints and the Modern Media, op. cit., pág. 418; VVAA, The Media Campaign Guide, 2004, pág. 3; K. R. Middleton/B. F. Chamberlain/M. D. BunKer, The Law of public communication, Wadsworth Pub. Co., 1997, pág. 535.

115 No obstante, aunque formalmente no exista un periodo definido como "campaña electoral", hay diferentes actividades que indican que ha dado comienzo esa "campaña electoral", por ejemplo, cuando los candidatos ofrecen ruedas de prensa para anunciar la presentación de sus candidaturas, o bien cuando ofrecen mítines o discursos electorales, cuando se suceden los actos para recogida de fondos, etc. Vid. 47 CFR 73, 1940 (f).

116 Communications Act, sección 315 (b).

11747 CFR 73, 1940 (a). Este derecho ya apareció en la Radio Act de 1927 que establecía la obligación de que las cadenas de radiodifusión que facilitaran tiempo de emisión a todos los candidatos electorales "legalmente calificados", debían ofrecer igualdad de condiciones a todos aquellos candidatos que concurrieran a las elecciones, es decir, que compiten por el mismo cargo electivo. Radio Act de 1927, 44 Stat. Sec. 18 (1927). En la doctrina, L.P. Devuin, «Political commercials in American presidential elections", en L. LeE KaID / C. Holz-BACHA, Political Advertising in Western Democracies. Parties \& Candidates on Television, 1995, pág. 191.

118 Sección 315 Communications Act; 47 CFR 73, 1940. 
en la idea de que todos los candidatos que cumplan con los requisitos legales tienen derecho a adquirir espacios de publicidad electoral y, por tanto, los medios de comunicación no pueden negarse a difundir espacios electorales de un candidato determinado por el simple hecho de que parezca tener pocas posibilidades de resultar elegido ${ }^{119}$. Por lo tanto, durante la fase de prenominación, todos los precandidatos de un mismo partido político que se presentan a las elecciones primarias para ser elegidos candidato a la presidencia por su partido son considerados, a estos efectos, "candidatos legalmente cualificados", de modo que debe garantizarse la "equal time rule" a todos ellos ${ }^{120}$.

En las elecciones presidenciales, todas las empresas de radiodifusión que emiten canales de radio o televisión por ondas terrestres y por satélite a permitir la adquisición de espacios de publicidad a todos los candidatos que lo soliciten ${ }^{121}$. De acuerdo con la "equal time rule" los medios de comunicación deben permitir la emisión de publicidad electoral a todos los candidatos que lo soliciten, deben proporcionarles "un tiempo igual" para la emisión de espacios, y, además, deben garantizar también la igualdad de trato en relación con las condiciones en que se produzcan o emitan dichos espacios, ya sea por lo que se refiere a las tarifas, horario de emisión o a la utilización de medios técnicos ${ }^{122}$.

En cuanto a la distribución de los espacios de publicidad electoral, no se establecen reglas respecto de la distribución de los espacios electorales, que quedan al libre arbitrio de los medios, aunque todos ellos deben respetar la obligación de garantizar un acceso razonable a todos los candidatos ${ }^{123}$. Por último, el Tribunal Supremo ha afirmado en varias ocasiones que los medios no pueden controlar el contenido de los espacios electorales a menos que exista una evidencia clara de que se está cometiendo un delito ${ }^{124}$.

119 FCC Political Primer, 100 FCC 2d. 1476 (1984), secc. 27. En caso contrario, se establece incluso que se puede revocar la licencia al medio de comunicación que se niegue a facilitar un acceso razonable a todos los candidatos legalmente cualificados, en este sentido, vid. 47 CFR 73, 1944 (a). En la doctrina, vid., K. R. Middleton/B. F. Chamberlain/M. D. Bunker, The Law of public communication, op. cit., pág. 538.

120 FCC Political Primer, 100 FCC 2d. 1476 (1984), secc. 29. El Tribunal de Apelación del Distrito de Columbia ratificó esta interpretación de la FCC en el caso Kay v. FCC, 443 F 2d. 638 (DC Cir. 1970).

121 Los operadores de cable no están obligados a ello, pero si aceptan la solicitud de uno de los candidatos, entonces quedan obligados a permitir a todos los demás adquirir espacios publicitarios en las mismas condiciones. Communications Act, $₫ 315$. Por lo que respecta a la radiodifusión por satélite, vid. Communications Act, $₫ 335$ (a). Para la televisión por cable, 47 CFR 76,205 (a).

122 Bella Sabzug, 25 FCC 2d. 117 (1970). En la doctrina, L. P. DevLIN, "Political commercials in American presidential elections", op. cit., pág. 186; K. R. MidDleton/B. F. Chamberlain/M. D. Bunker, The Law of public communication, op. cit., pág. 538; F. Rowan, Broadcast Fairness, Doctrine, Practice, Prospects. A Reappraisal of the Fairness Doctrine and Equal Time Rule, op. cit., pág. 7.

12347 CFR 73, 1941. Vid., Martin-Trigona, 64 FCC 2d. 1087 (1987).

124 Communications Act, sección 315 (a). Letter to Lonnie King, 36 FCC 2d. 635 (1972). 47 USC 315.a (1995); VVAA, The Media Campaign Guide, op. cit., pág. 15; B. CarTer M. A. Frankin/J. B. Wright, The first Amendment and the Fifth State. Regulation of electronic mass media, Foundation Press, 1986, pág. 170. 
Finalmente, y para concluir, nos referiremos brevemente al régimen jurídico de los debates electorales. En los Estados Unidos, en un primer momento, los debates electorales estaban sujetos a la regla general del «equal time", de modo que los medios de comunicación estaban obligados a permitir un acceso razonable de todos los candidatos. Esto significaba, por tanto, que debían participar todos los candidatos y con el mismo tiempo. Sin embargo, posteriormente, se reformó la Communications Act y los debates pasaron a ser "programas informativos de interés general" que, de acuerdo con la nueva regulación, quedan exentos de cumplir con la regla de la igualdad de oportunidades. Así pues, en la actualidad se celebran sólo debates a dos, ya que éstos no están sujetos a la "equal time rule", excluyendo, de este modo, a terceros candidatos ${ }^{125}$.

TrtLE: The Presidential election in the United States.

ABSTRACT: The process of electing the President in the United States is characterized for its complexity, because it differs from state to state. This essay explains the presidential election's process and reviews the laws, activities, and customs that govern each of its four stages: the pre-nomination phase, in which candidates compete in state primary elections and caucuses for delegates to the National Party Conventions, the national nominating conventions, the general election, and the Electoral College. The essay also focuses on the general election campaign, especially on the funding of the presidential campaign and the access of the candidates to the media.

REsUmen: El sistema de elección del Presidente de los Estados Unidos se caracteriza por su complejidad, ya que no existe un régimen jurídico bomogéneo en toda la Federación, sino que varía de un Estado a otro. El presente trabajo tiene por objeto el análisis del régimen jurídico de las elecciones presidenciales en los Estados Unidos en sus distintas fases: la primera, la fase de pre-nominación, en la cual los precandidatos compiten entre si en las elecciones primrias o caucuses para lograr delegados que les representen en las convenciones nacionales de cada uno de los partidos politicos; la segunda, las convenciones nacionales de los partidos, en la que se elige al candidato a la presidencia del partido político; la tercera, la jornada electoral y, finalmente, la posterior elección del Presidente a través del Congreso Electoral. Este trabajo concluye con una breve referencia a la campaña electoral en las elecciones presidenciales, prestando especial atención a la financiación y al acceso de los candidatos a los medios de comunicación.

Key words: Presidential election. Primary election. Caucus. Electoral campaign. American electoral system.

Palabras Clave: Elecciones presidenciales. Primarias. Financiación de los partidos politicos. Sistema electoral norteamericano.

125 J. Z. Zelezny, Communications Law, Liberties, Restraints and the Modern Media, op. cit., pág. 419. 